\title{
Energy Evolution Characteristics and Distribution Laws of Rock Materials under Triaxial Cyclic Loading and Unloading Compression
}

\author{
Mingwei Zhang, Qingbin Meng, and Shengdong Liu \\ State Key Laboratory for Geomechanics and Deep Underground Engineering, China University of Mining and Technology, \\ Xuzhou 221116, China
}

Correspondence should be addressed to Mingwei Zhang; mingweizhang@cumt.edu.cn

Received 12 July 2017; Accepted 25 September 2017; Published 29 October 2017

Academic Editor: Michele Zappalorto

Copyright (c) 2017 Mingwei Zhang et al. This is an open access article distributed under the Creative Commons Attribution License, which permits unrestricted use, distribution, and reproduction in any medium, provided the original work is properly cited.

To explore the influence of confining pressure on the energy evolution characteristics of loaded rocks, triaxial cyclic loadingunloading experiments on sandstones were carried out under 6 kinds of confining pressures using the axial loading and circumferential deforming control modes. Total energy density, elastic energy density, and dissipated energy density absorbed by rock specimens under different confining pressures were obtained. The confining pressure effect of the evolution process and distribution law in energy accumulation and dissipation was analyzed. Energy conversion mechanism from rock deformation to failure was revealed, and energy conversion equations in different stress-strain stages were established. The method of representing the rock energy accumulation, dissipation, and release behaviors by energy storage limit density, maximum dissipated energy density, and residual elastic energy density was established. The rock showed that, with the increase of confining pressure, the characteristic energy density of rock increased in the power exponent form, and the energy storage limit density increased faster than the maximum dissipated energy density. The greater the confining pressure was, the greater the proportion of elastic energy before peak was. It is indicated that the confining pressure increased the energy inputting intensity, improved the energy accumulating efficiency, and inhibited the energy releasing degree.

\section{Introduction}

According to the laws of thermodynamics, energy conversion is an essential characteristic of material physical processes. In the final analysis, rock failure is a state instability phenomenon driven by energy [1], and the dynamic failure of rock is a result of the rapid release of elastic energy aggregated inside a rock when failure reaches the intensity limit [24]. Energy evolution runs through the entire process of rock deformation and failure. The outside world often inputs energy to rock in the form of mechanical energy, part of which is transformed into elastic energy to accumulate in the rock and the rest of which dissipates in the forms of damage energy and plastic energy that cause structural changes in the rock material. When a rock reaches its intensity limit, the elastic energy in it is released and transformed into the kinetic energy of rock fragments. Studying the laws of rock deformation and failure from the perspective of energy is closer to the essence of its failure. This approach can enrich and deepen understanding of the mechanical behavior of loading rock and promote research on rock burst, large-area roof weighting, coal and gas outburst, and other coal and rock dynamic disasters.

From the perspective of mechanics, the deformation and failure of rock is actually a process from local dissipation to local failure and finally to overall catastrophe. From the perspective of thermodynamics, the deformation, failure, and catastrophe process is an irreversible process of energy dissipation, including energy dissipation and energy release. Rock deformation and failure is the comprehensive result of energy dissipation and release. Energy dissipation damages rock and results in lithologic deterioration and loss of strength. Energy 
release is the internal reason for the sudden overall failure of rock. In the process of rock deformation and failure, energy plays a fundamental role. The unstable failure of rock is the result of sudden energy release from the rock, which is catastrophic energy dissipation under certain conditions. Therefore, it is of prime significance to study the energy state during the entire process of rock deformation and failure [58]. In terms of the energy evolution law for loading rock, studies mainly use rock mechanics experiments to obtain the varying regularity of elastic energy and the dissipated energy in rock in different stages of deformation and failure and to analyze correlations between regularity and rock mechanics behavior.

In recent years, scholars have conducted much research by experimental means and gained a preliminary understanding of the energy evolution law for loading rock. They have also achieved certain research progress in describing the deformation and failure behavior of rock through energy analysis. For example, Tsoutrelis and Exadaktylos analyzed the energy characteristics of rock before the peak based on uniaxial and triaxial rock compression experiments in the lab [9]. Gaziev proposed that the failure of the unit cell does not begin until the shape change reaches a limiting value and that continuous accumulation of total strain energy is a necessary condition for material failure [10]. Holcomb noted that the stress-strain curve of rock was characterized by nonlinearity, hysteresis, discrete memory, and energy dissipation under uniaxial cyclic loading [11]. Tutuncu et al. studied the mechanical behavior of sedimentary rock under uniaxial cyclic stress and found that the plastic-loop characteristic of the stress-strain curve was correlated with the frequency of load application and the strain amplitude and that it affected accumulation and dissipation of rock energy $[12,13]$. Wong et al. studied the mechanical behavior characteristics of rock under dynamic loading and revealed the failure law of rock $[14,15]$. Deng et al. conducted dynamic uniaxial compression experiments on granite and sandstone at 5 different impact speeds using a Split-Hopkinson Pressure Bar (SHPB) test device and revealed energy dissipation characteristics of rock dynamic deformation and failure [16]. Li et al. studied energy dissipation characteristics of rock under cycling impact and established a relationship between the accumulated absorption energy of rock per unit volume under cycling impact load and the size of rock broken [17]. Zhang et al. researched the distribution law of the impact loading rate on energy dissipation and release of gabbro and marble [18]. Xie et al. performed thermodynamic analysis of the rock deformation and failure process, revealed the internal relationship between rock failure and energy accumulation and release, defined concepts of unit dissipated energy, releasable strain energy, strength loss, and overall failure, and established rock strength and an overall failure criterion based on an energy dissipation and release principle [1]. Li et al. did uniaxial compression experiments on coarsegrained rock under different strain rates, revealed the influence of the loading strain rate on strain energy dissipation and release of the rock, discussed the energy mechanism of the rock failure evolution, and indicated that when there was more dissipated energy under uniaxial compression before the peak and higher strength, the releasable elastic strain energy and release speed after peak were greater, the extensional penetrating rupture feature of rock was stronger, and the number of broken blocks was greater; energy dissipation caused rock failure, and strength loss and energy release led to macroscopic failure surface penetration and overall rock failure [19]. Gao et al. conducted uniaxial cyclic loading-unloading experiments on red sandstone and revealed the nonlinear characteristic of rock energy evolution under uniaxial compression experimental conditions [20]. Meng et al. performed uniaxial compression experiments and uniaxial loading-unloading experiments on red sandstones under different sizes and loading rates using an MTS 815 rock mechanics test system, provided a rock energy calculation method using the cyclic loading-unloading stressstrain curve, obtained total absorbed energy, elastic energy, and dissipated energy of rock under different sizes of rock specimens and loading rates, and revealed the evolution and distribution law of energy accumulation and dissipation of rock before the peak in the process of rock deformation and failure [21, 22]. Hua and You analyzed the source of rock energy release in the unloading failure process and noted that unloading failure was caused by the release of a large amount of elastic energy aggregated before rock unloading [23]. Peng et al. analyzed the damage evolution behavior and the dissipated energy characteristics of coal through triaxial compression experiments on coals under 5 types of confining pressures and defined the damage variable based on energy analysis and its evolution law [24]. Yang et al. conducted triaxial compression experiments on tight sandstone to analyze the relationships among elastic energy density, dissipated energy density, and confining pressure [25]. Ju et al. studied the influence of porosity on rock energy dissipation and the energy dissipation situation during critical rock failure through methods of experiment and numerical simulation [26]. Under the same impact rate, with an increase of porosity of the rock, the energy dissipated by the rock increased, and the energy dissipated by critical failure decreased. Rock energy dissipation reflected internal damage and failure of rock to a certain extent. Song et al. studied the correlation between dissipated energy and electromagnetic radiation in the damage and failure process of coal [27].

In general, the research work noted above greatly promotes the development of rock energy theory, but it mainly focuses on energy characteristics at the yield point and peak point, before the peak or at other particular stages, and research on energy evolution throughout the rock deformation and failure process and its distribution law is not sufficient. In particular, research on the confining pressure effect of absorbed energy, aggregated energy, dissipated energy, and released energy after peak is not extensive. Thus, this paper describes triaxial cyclic loading-unloading experiments under 6 types of confining pressures to obtain the evolution regularity of elastic energy and dissipated energy in the entire process of rock deformation and failure (including stages before and after the peak of the stressstrain curve), to reveal the confining effect of rock energy accumulation, dissipation, and release characteristics, and to provide both a theoretical foundation for studying the 
damage and failure mechanism of rock from the perspective of energy and guidance for forecasting the failure process in rock engineering and for studying the dynamic disaster mechanism of coal and the corresponding prevention strategy.

\section{Energy Calculation Method and Experimental Scheme for Rock Triaxial Loading}

2.1. Strain Energy Density Calculation of the Triaxial Loaded Rock. The first law of thermodynamics states that thermal energy can be transferred, its form can be transformed, and the total energy in various forms is constant in the process of transfer and conversion. In the entire process of rock deformation and failure, rock continuously exchanges energy with the external environment, namely, thermal energy exchange and mechanical energy exchange. The thermal energy can be transformed into internal energy to cause an increase in rock temperature, resulting in temperature deformation. The potential energy is produced in the case of boundary conditions such as nonuniform temperature deformation or limited temperature deformation. The energy input from outside is mainly mechanical energy (work on the rock specimen performed by the tester). It is transformed into elastic deformation energy stored during elastic deformation, damage energy (surface energy) during cracking, and rock block kinetic energy, frictional heat energy, all types of radiant energy, and others after unstable failure.

According to the first law of thermodynamics,

$$
U=Q+W
$$

In the formula, $U$ is the internal energy increment of the system, J; Q refers to the heat exchange between the system and the environment, J; and $W$ is the work exchange between the system and the environment, J.

For the triaxial experiments on rock, work was done on the rock specimen by the tester from the loading of a hydrostatic stress state $\left(\sigma_{1}=\sigma_{2}=\sigma_{3}\right)$. After the hydrostatic stress state was achieved, the axial stress $\sigma_{1}$ in compression constantly worked on the rock specimen. In the circumferential direction, due to expansion deformation, the confining pressure $\sigma_{3}$ did negative work on the rock specimen. In other words, after the hydrostatic stress state, the rock specimen absorbed energy in axial compression deformation and dissipated energy in circumferential expansion deformation. Therefore, if heat exchange between the rock system and the environment is not considered, the total energy $u^{0}$ of the rock specimen in the experimental process can be expressed as

$$
u^{0}=u_{1}^{0}+u_{2}^{0}+u_{3}^{0}
$$

where $u_{1}^{0}$ is the absorbed energy in rock compression under the axial stress $\sigma_{1} ; u_{2}^{0}$ is the dissipated energy in rock expansion under the confining pressure $\sigma_{3}$; and $u_{3}^{0}$ is the absorbed energy of the rock specimen in the hydrostatic stress state. The energy $u_{3}^{0}$ can be solved according to elastic mechanics:

$$
u_{3}^{0}=\frac{1}{2} \sigma_{1} \varepsilon_{1}^{e}+\frac{1}{2} \sigma_{2} \varepsilon_{2}^{e}+\frac{1}{2} \sigma_{3} \varepsilon_{3}^{e}=\frac{3(1-2 \mu)}{2 E}\left(\sigma_{3}\right)^{2},
$$

where $E$ is the elastic modulus, $\mathrm{MPa} ; \mu$ is Poisson's ratio.

Thus, from the initial state of the rock specimen to loading to the hydrostatic stress state, there was also energy evolution within the rock specimen. During the axial loadingunloading stages under fixed confining pressure after the hydrostatic stress state, the rock also dissipated energy in the direction of the confining pressure. Since the experiment did not consider the condition of unloading confining pressure, the evolution of the circumferential rock energy was limited. At the same time, considering that quantities of energy compositions were small and did not directly cause failure of the rock specimen, the analysis in this paper ignores energy evolution behavior in these two aspects. The energy evolution of loading rock was roughly divided into 4 processes, namely, energy input, accumulation, dissipation, and release. Since many types of energy were involved, it was difficult to monitor the evolution process of each type of energy. Considering the reversibility of elastic energy and the irreversibility of dissipated energy, this paper presented systematic research on elastic energy and dissipated energy only. In addition, energy density calculated in the paper referred to input, accumulation, dissipation, and release of axial energy density, which was calculated from applying axial pressure after the hydrostatic stress state.

Considering the deformation of a rock unit under the effect of an external force, it was assumed that there was no heat exchange with the outside world during the physical process. In other words, it was a closed system. According to the law of conservation of energy,

$$
u^{0}=u^{e}+u^{d}
$$

where $u^{0}$ is the total energy absorbed by the rock, namely, the external energy input (work done on the rock by an external force); $u^{e}$ is the elastic energy aggregated in the rock; and $u^{d}$ is the energy dissipated by the rock in the loading process, which is mainly used for internal damage and plastic deformation.

A rock is a type of natural geological material containing microcracks, porosity, joints, and other defects that lead to imperfect elasticity during rock deformation. Figure 1 shows a typical stress-strain curve for a rock in triaxial cyclic loading-unloading experiments. The figure shows that when unloading after loading to a certain stress level, the unloading curve does not coincide with the loading curve. It is lower than the original loading curve rather than following its path, forming a closed plastic loop (closed-loop curve). The formation of a plastic loop reflects work done for internal crack formation, extension, and crack closure friction of the rock specimen under loading. In other words, the area of the plastic loop reflects the amount of energy dissipated from the rock.

In accordance with the opinion that elastic energy is reversible and the rock stress-strain curve characteristics in 


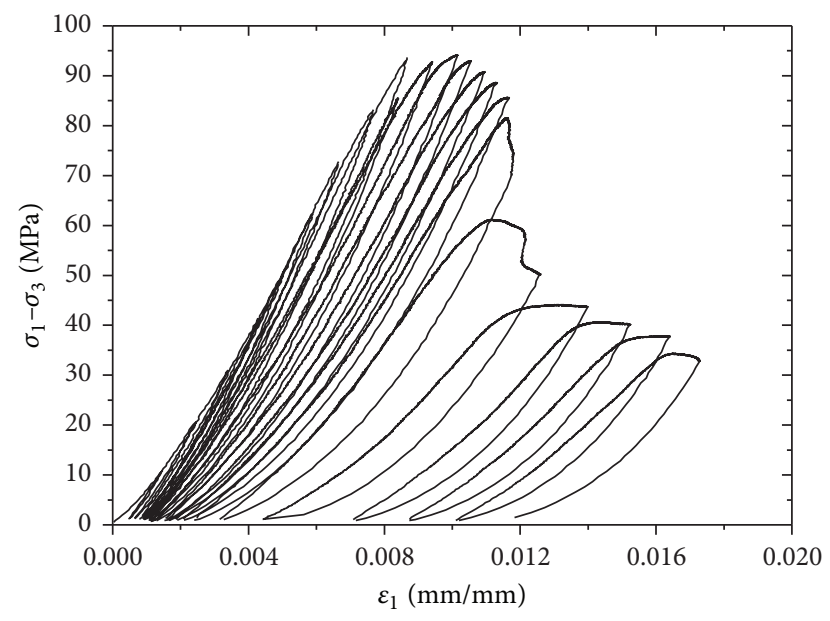

Figure 1: A complete stress-strain curve of the red sandstone specimen during the triaxial cyclic loading-unloading compression $\left(\sigma_{3}=10 \mathrm{MPa}\right)$.

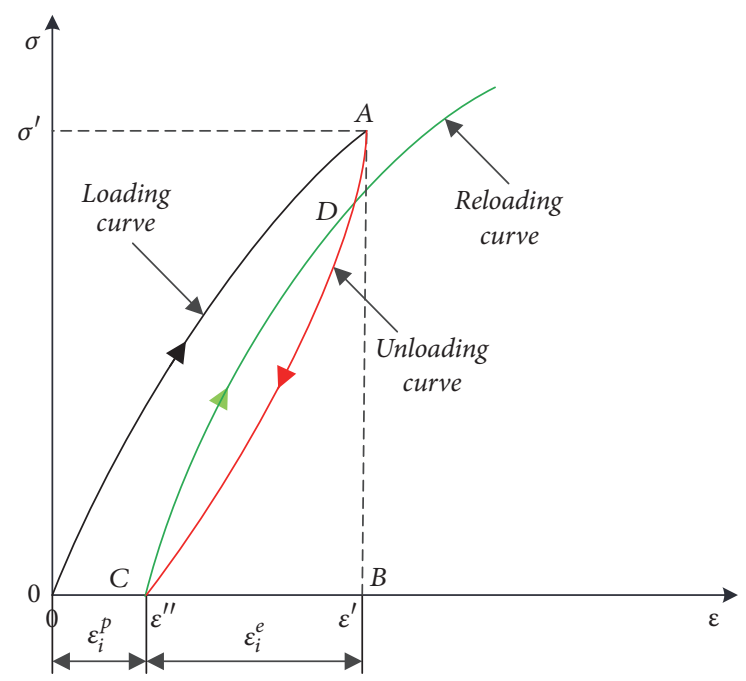

FIGURE 2: Variation of the elastic energy density and the dissipated energy density per unit rock volume under loading-unloading conditions.

a triaxial cyclic loading-unloading experiment, the elastic energy and dissipated energy can be calculated from the rock loading-unloading stress-strain curve. The energy released after unloading can be regarded as elastic energy aggregated by the rock at a stress level during unloading, and the value reduced relative to total energy absorbed by the rock during loading is the dissipated energy of the rock at a stress level. The correlation between elastic energy density $u_{i}^{e}$ and dissipated energy density $u_{i}^{d}$ in a unit volume of loadingunloading curves at stress level $\sigma^{\prime}$ is shown in Figure 2.

The area under the loading curve in a triaxial cyclic loading-unloading stress-strain curve is the energy density absorbed by the rock specimen, namely, the work done by the tester on the rock specimen. The area under the unloading curve is the elastic energy density released by the rock specimen, namely, the recoverable strain energy
TABLE 1: Triaxial cyclic loading-unloading experimental schemes of sandstone specimens.

\begin{tabular}{lc}
\hline$\sigma_{3}(\mathrm{MPa})$ & Rock specimens \\
\hline 0 & $\mathrm{U}-1 \#, \mathrm{U}-2 \#, \mathrm{U}-3 \#$ \\
5 & $1 \#, 2 \#, 3 \#$ \\
10 & $4 \#, 5 \#, 6 \#$ \\
15 & $7 \#, 8 \#, 9 \#$ \\
20 & $10 \#, 11 \#, 12 \#$ \\
25 & $13 \#, 14 \#, 15 \#$ \\
30 & $16 \#, 17 \#, 18 \#$ \\
\hline
\end{tabular}

released by the rock specimen after unit unloading. The absorbed energy density minus the elastic energy density is the dissipated energy density, namely, the area between loading and unloading curves, which is used for failure and elastic deformation inside the rock unit.

$$
\begin{aligned}
& u_{i}^{e}=\int_{\varepsilon^{\prime \prime}}^{\varepsilon^{\prime}} \sigma_{i} d \varepsilon_{i}, \\
& u_{i}^{d}=\int_{0}^{\varepsilon^{\prime}} \sigma_{i} d \varepsilon_{1}-\int_{\varepsilon^{\prime}}^{\varepsilon^{\prime \prime}} \sigma_{i} d \varepsilon_{i} .
\end{aligned}
$$

In the formula, $\sigma^{\prime}$ is the stress at any point on the stress-strain curve, $\mathrm{MPa} ; \varepsilon^{\prime}$ is the strain corresponding to $\sigma^{\prime}, \mathrm{mm} / \mathrm{mm}$; and $\varepsilon^{\prime \prime}$ is the strain when $\sigma^{\prime}$ is unloaded to 0 , $\mathrm{mm} / \mathrm{mm}$.

2.2. Experimental Equipment and Methods. To reveal the influence of confining pressure on rock energy evolution, the triaxial cyclic loading-unloading experiments on red sandstone specimens under six groups of confining pressures (5, $10,15,20,25$, and $30 \mathrm{MPa}$ ) were carried out. The experimental scheme was detailed in Table 1.

The overall cyclic loading-unloading process was controlled by the MTS 815 rock mechanics test system with the axial loading and circumferential deforming control methods (as shown in Figure 3). The system was composed of a loading system, a testing system, and a control system. With several different control modes, including axial stress control, axial stroke control, axial strain control, and circular strain control, this facility can meet the requirements of various experimental designs. To eliminate environmental noise, the noise level of the loading system was tested beforehand, and a digital filter was implemented during data acquisition. The servo sensitivity, strain loading rate, and the minimum sampling interval for the MTS 815 system were $290 \mathrm{~Hz}, 10^{-7}-10^{-2} / \mathrm{s}$, and $50 \mu \mathrm{s}$, respectively. At the initial stage, the axial loading control method was used for the constant gradient loading and unloading with $20 \mathrm{kN}$ as a cycle. Axial loading and unloading rates were $0.5 \mathrm{kN} / \mathrm{s}$ and $2.0 \mathrm{kN} / \mathrm{s}$, respectively. The confining pressure remained the same at the unloading stage. To prevent the sudden failure of rock specimens when being unloaded at the peak or after the peak, when the load reached to $80 \%$ of the peak intensity, the loading mean was converted into the circumferential deforming control. The circumferential loading rate was $0.001 \mathrm{~mm} / \mathrm{s}$. The increment 


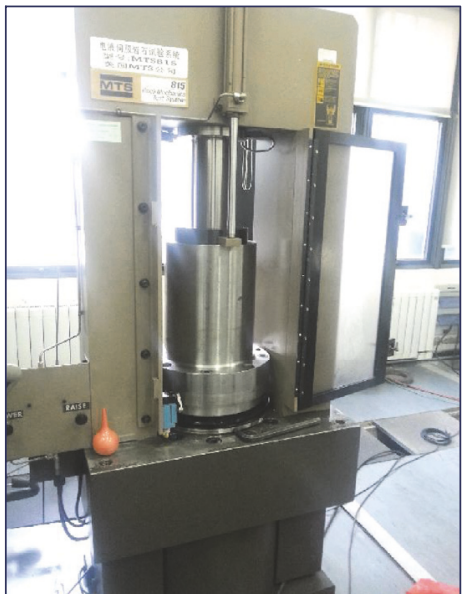

(a)

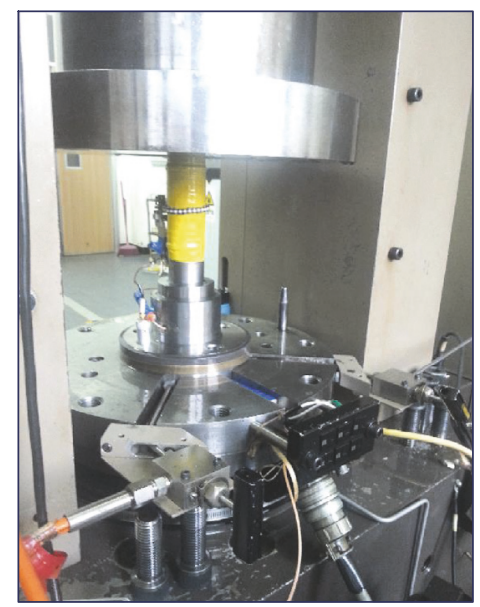

(c)

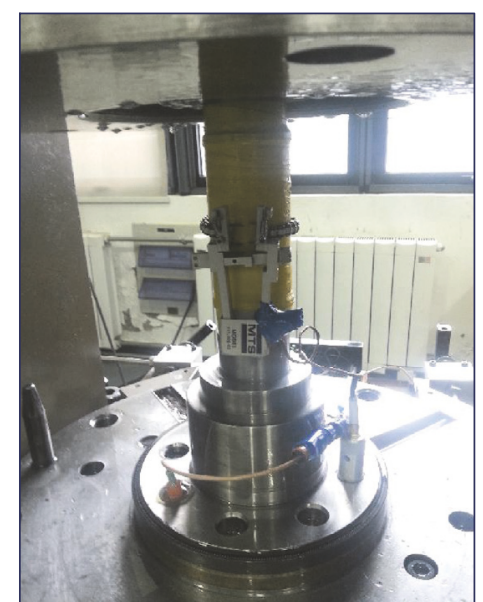

(b)

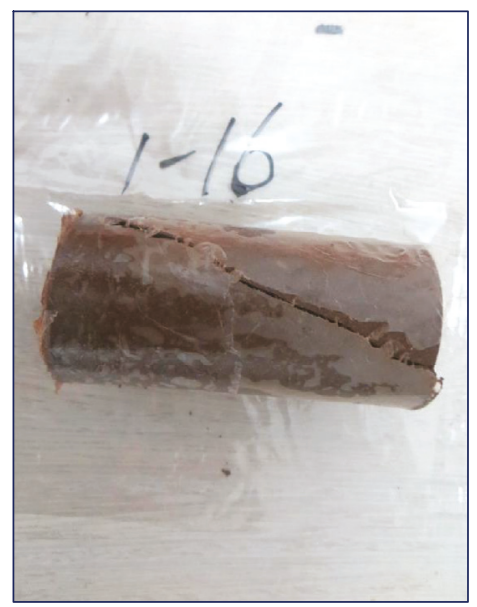

(d)

FIGURE 3: The MTS 815 rock mechanics test system applied in rock mechanical experiments. (a) Confining device. ((b) and (c)) Installation of rock specimens. (d) Rock failure after triaxial compression.

of every circumferential loading point is $0.2 \mathrm{~mm}$. The axial loading rate was $2.0 \mathrm{kN} / \mathrm{s}$. Experiment was terminated until reaching the residual strength.

According to the experimental need, the specific steps were as follows: (1) preparation: numbering the rock specimens, measuring the diameters, heights, and weights, covering the thin heat-shrinkable tube surrounding rock specimens, wrapping them uniformly with the waterproof tap to prevent rock specimens from the hydraulic oil, and finally placing the rock specimens in the triaxial pressure chamber; (2) loading to the preset confining pressure value according to the hydrostatic stress, resetting the axial displacement and circumferential displacement and then starting the loading experiment following the design scheme; and keeping the confining pressure unchanged during unloading process; (3) experimental path: $0 \rightarrow 20 \mathrm{kN} \rightarrow 0 \rightarrow 40 \mathrm{kN} \rightarrow 0 \rightarrow 60 \mathrm{kN} \rightarrow$ $0 \rightarrow 80 \mathrm{kN} \rightarrow 0 \rightarrow 100 \mathrm{kN} \rightarrow 0 \rightarrow 120 \mathrm{kN} \rightarrow 0 \rightarrow 140 \mathrm{kN} \rightarrow$ $0 \rightarrow \cdots \rightarrow \sigma_{80 \%}$ (load reaches $80 \%$ of the peak intensity; the circumferential deformation is $\mathrm{d} 0) \rightarrow 0 \rightarrow \mathrm{d} 0+0.2 \mathrm{~mm} \rightarrow 0$ $\rightarrow \mathrm{d} 0+0.4 \mathrm{~mm} \rightarrow 0 \rightarrow \mathrm{d} 0+0.6 \mathrm{~mm} \rightarrow 0 \rightarrow \cdots \rightarrow$ residual strength (experiment ended).

\section{Rock Energy Evolution and Distribution Law under Triaxial Cyclic Loading-Unloading Conditions}

3.1. Energy Evolution Law of the Triaxial Loaded Rock Specimens. The total absorbed energy density, elastic energy density, and dissipated energy density of rocks under different confining pressures can be calculated according to the rock energy calculation formula and the stress-strain curve from triaxial cyclic loading-unloading processes to reveal the influence of the confining pressure on the energy evolution law of rock specimens. The stress-strain and energy densitystrain curves of rock specimens under uniaxial cyclic loadingunloading conditions are shown in Figure 4, the energy density-strain curves of rock specimens under triaxial cyclic loading-unloading conditions are shown in Figure 5, and 


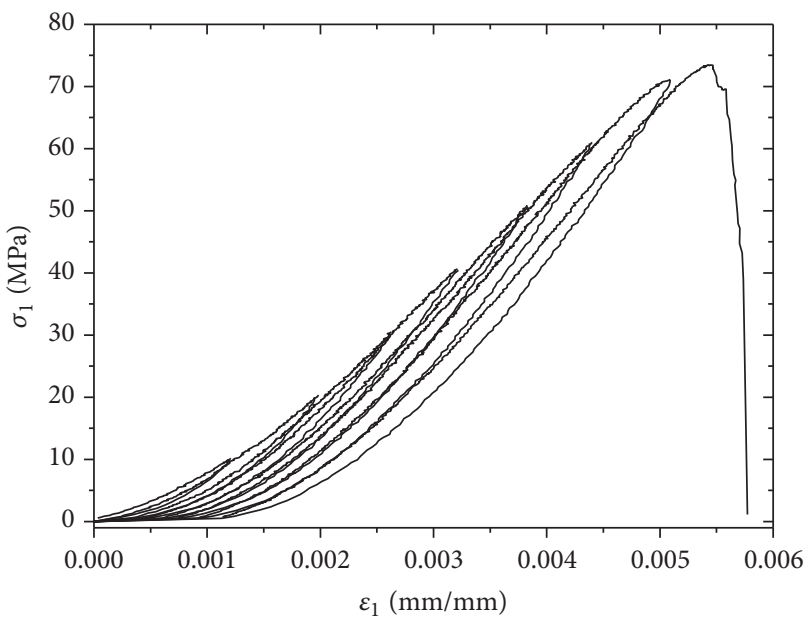

(a) Stress versus strain

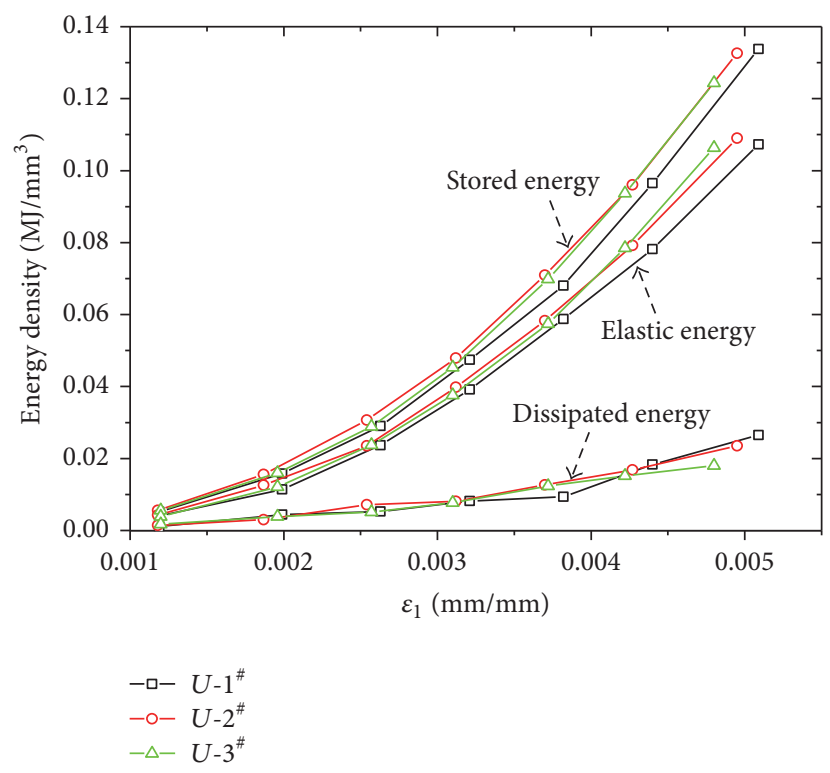

(b) Energy density versus strain

FIGURE 4: The stress-strain relationship and the energy density-strain relationship of red sandstone specimens under the uniaxial cyclic loading-unloading compressions.

the energy density-strain curves of rock specimens under different confining pressures are shown in Figure 6.

From Figures 4 and 5, (1) before the peak, during uniaxial cyclic loading-unloading $\left(\sigma_{3}=0 \mathrm{MPa}\right)$, when the load reached the stress peak, the stress-strain curves decreased sharply; rock specimens experienced sudden failure and instability and lost bearing capacity in a short time. As a result, there was no time to record test data. When confining pressure was applied $\left(\sigma_{3}>0 \mathrm{MPa}\right)$, before the peak, the energy evolution behavior of the rock was similar to that in the uniaxial cyclic loading-unloading experiment. The absorbed total energy density, aggregated elastic energy density, and dissipated energy density of rock specimens all increased with the increase of axial strain. The tester continually transferred mechanical energy to the rock specimens. The rock specimens aggregated energy on one hand and dissipated energy to cause changes in their own structures on the other hand. The aggregated elastic energy of rock specimens increased faster than the dissipated energy, indicating that, before the peak, the energy behavior of the rock was mainly reflected as energy accumulation with elastic energy dominant. The elastic energy increased slowly at first and rapidly later. It increased slowly at the compaction stage of initial loading. This behavior occurred because primary pores in rock specimens were compressed, leading to small initial stiffness (initial elastic modulus) and low efficiency of energy conversion. The release of elastic energy and the increase of dissipated energy caused a reduction in the energy storage capacity of the rock specimens so that rock deformation increased gradually and tended to failure. When rock specimens were about to fail, the dissipated energy increased rapidly, and the elastic energy increased more slowly, which indicated that the rock structure was changed and that internal crack extension and connection phenomena were clear. (2) After the peak, connection and extension microcracks and the formation process of macro failure surfaces in rock specimens promoted the conversion of elastic energy stored in them into other forms of energy to be dissipated and released, which caused a rapid decrease of the elastic energy density and a significant increase of the dissipated energy density. As a result, the dissipated energy density gradually exceeded the elastic energy density until dissipated energy was dominant. Their change curves had peaks. The peak of elastic energy occurred earlier than that of dissipated energy. With the increase of the failure degree of rock specimens during loading and the development to a residual phase, both elastic energy and dissipated energy were at low levels.

According to Figure 6, (1) before the peak, the elastic energy density-strain curves under different confining pressures changed consistently. They increased with the increase of the loading level until reaching the peak of elastic energy density (the storage limit of the rock). Then, they decreased to small values after the peak. With the increase of the confining pressure, the slopes of the elastic energy densitystrain curves before the peak showed a trend of increase, indicating that confining pressure improved the efficiency of energy accumulation. (2) Before the peak, the dissipated energy density-strain curves under different confining pressures changed consistently. With the increase of the loading level, they increased slowly. When the specimen was close to failure, the dissipated energy increased dramatically to form a peak point, characterizing the occurrence of a macro fracture. It decreased to a small value after the peak. With the increase of confining pressure, the slopes of the dissipated energy density-strain curves before the peak showed a trend 

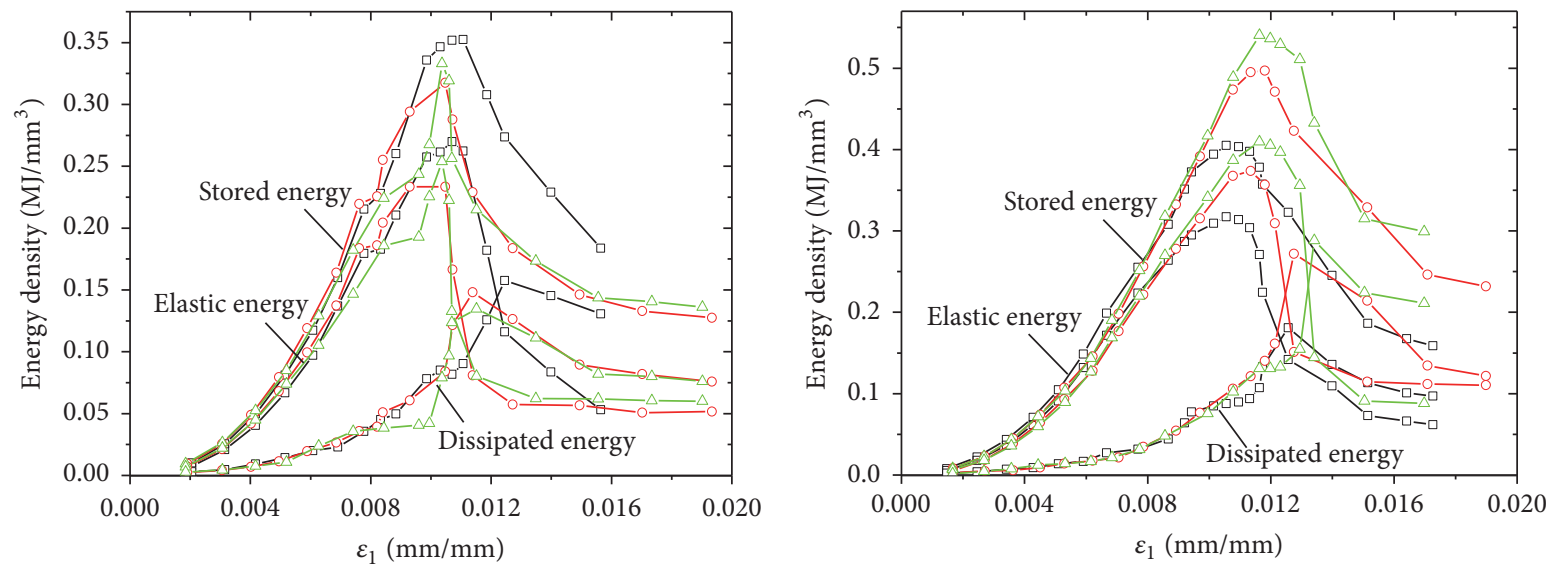

$$
\begin{aligned}
& -\square-1^{\#} \\
& -\circ-2^{\#} \\
& -\triangle-3^{\#}
\end{aligned}
$$

$$
\begin{aligned}
& -\square-4^{\#} \\
& -\circ-5^{\#} \\
& -\triangle-6^{\#}
\end{aligned}
$$

(a) $\sigma_{3}=5 \mathrm{MPa}$
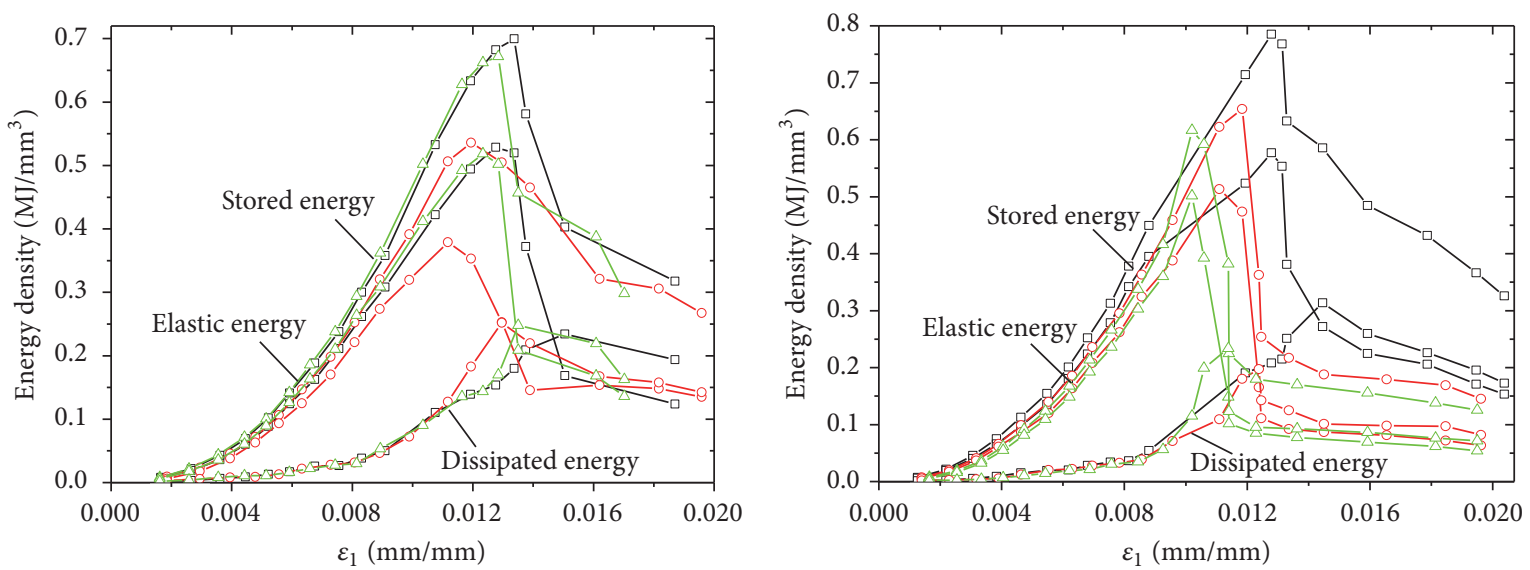

$$
\begin{aligned}
& -\square-7^{\#} \\
& -\circ-8^{\#} \\
& -\triangle-9^{\#}
\end{aligned}
$$

$$
\begin{aligned}
& -\square-10^{\#} \\
& -\circ-11^{\#} \\
& -\triangle-12^{\#}
\end{aligned}
$$

(c) $\sigma_{3}=15 \mathrm{MPa}$
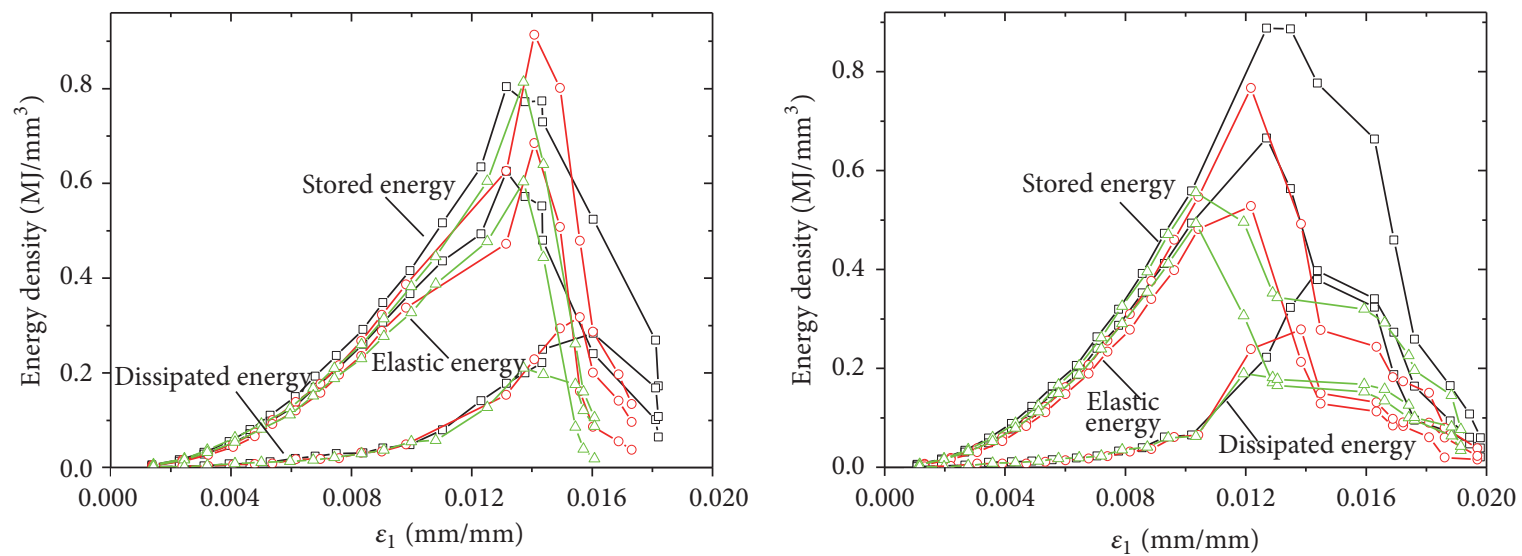

$$
\begin{aligned}
& -\square-13^{\#} \\
& -\circ-14^{\#} \\
& -\triangle-15^{\#}
\end{aligned}
$$$$
\begin{aligned}
& -\square-16^{\#} \\
& -\circ-17^{\#} \\
& -\triangle-18^{\#}
\end{aligned}
$$

(e) $\sigma_{3}=25 \mathrm{MPa}$

(f) $\sigma_{3}=30 \mathrm{MPa}$

FIGURE 5: Relationships of the rock energy density and the strain under triaxial cyclic loading-unloading compressions. 


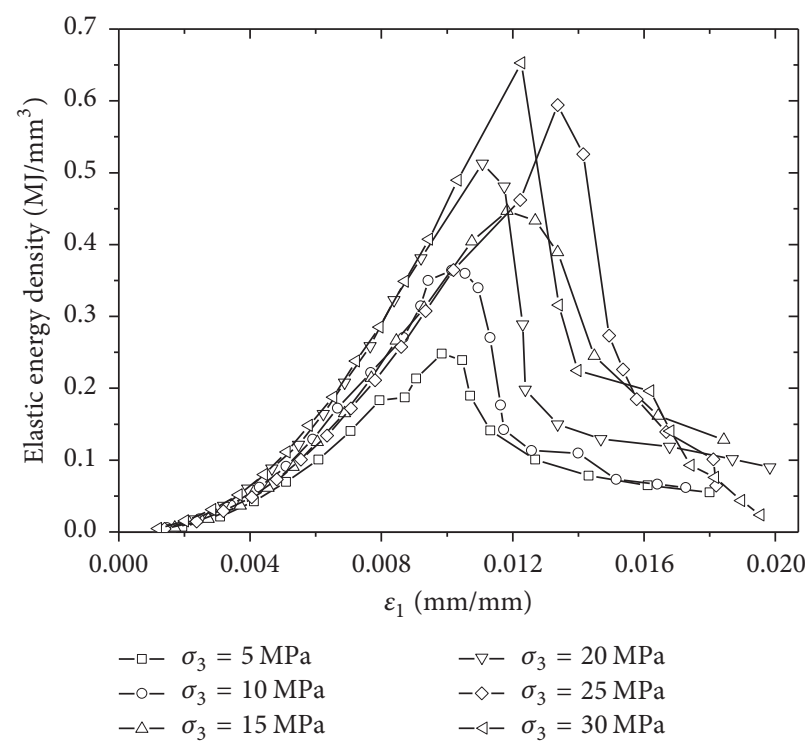

(a) Elastic energy density-strain

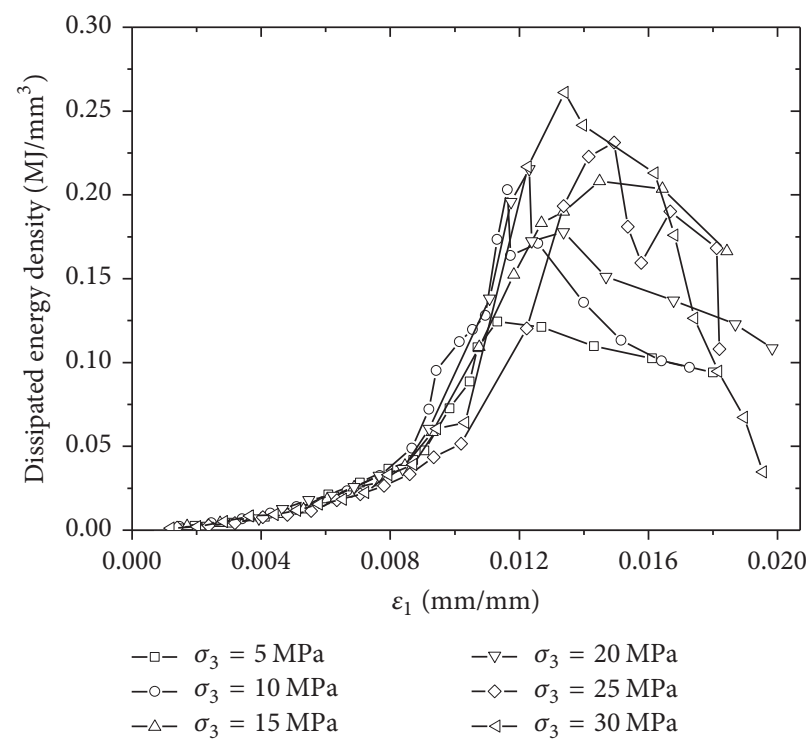

(b) Dissipated energy density-strain

FIGURE 6: Relationships of the rock energy density and the strain under different confining pressure conditions.

of decrease, indicating that the confining pressure reduced the degree of energy release.

To quantitatively describe the effect of confining pressure on rock energy evolution, three characteristic energy density parameters were proposed. The maximum elastic energy density (peak) was defined as the energy storage limit of the rock, which was used to characterize the capacity of the rock to accumulate elastic energy. The greater the energy storage limit of the rock was, the less susceptible it was to damage due to the drive of energy. The residual value after the great release of elastic energy density for the first time after the peak was the residual elastic energy density, which was used to characterize the capacity to release elastic deformation energy after the peak. The greater the residual elastic energy density was, the less thoroughly the rock energy was released. The maximum value of the dissipated energy density was defined as the maximum dissipated energy density, which was used to characterize the energy dissipation capacity of the rock. The greater the maximum dissipated energy density was, the more susceptible the rock was to suffer damage and plastic slip, thereby reducing its energy storage limit. The average of the three characteristic energy density parameters of rock under different confining pressures could be calculated, as shown in Table 2.

The change curve of the characteristic energy density with confining pressure is shown in Figure 7. The fitting functions of the three characteristic energy density parameters were as follows:

$$
\begin{array}{r}
u_{\max }^{e}=-0.81661 e^{-\sigma_{3} / 27.90342}+0.92581 \\
\\
u_{r}^{e}=-0.22525^{-\sigma_{3} / 7.94849}+0.24700 \\
\left(R^{2}=0.99755\right), \\
\left(R^{2}=0.96618\right)
\end{array}
$$

TABLE 2: Rock characteristic energy densities in different confining pressure conditions.

\begin{tabular}{lccc}
\hline$\sigma_{3}(\mathrm{MPa})$ & $u_{\max }^{e}\left(\mathrm{MJ} / \mathrm{mm}^{3}\right)$ & $u_{r}^{e}\left(\mathrm{MJ} / \mathrm{mm}^{3}\right)$ & $u_{\max }^{d}\left(\mathrm{MJ} / \mathrm{mm}^{3}\right)$ \\
\hline 0 & 0.1043 & 0.0000 & 0.0212 \\
5 & 0.2483 & 0.0782 & 0.1243 \\
10 & 0.3641 & 0.1096 & 0.1965 \\
15 & 0.4466 & 0.1281 & 0.2082 \\
20 & 0.5129 & 0.1295 & 0.2153 \\
25 & 0.5941 & 0.1391 & 0.2261 \\
30 & 0.6527 & 0.1405 & 0.2610 \\
\hline
\end{tabular}

$$
\begin{aligned}
& u_{\max }^{d}=-0.13957 e^{-\sigma_{3} / 6.35320}+0.14002 \\
& \left(R^{2}=0.99664\right) .
\end{aligned}
$$

According to Figure 7, (1) with the increase of the confining pressure, the energy storage limit density of the rock increased dramatically in form of a power exponent. It increased significantly with confining pressure before $20 \mathrm{MPa}$. When the confining pressure was $5 \mathrm{MPa}$, it was 2.4 times greater than that without confining pressure. When the confining pressure was $10 \mathrm{MPa}$, it was 3.5 times greater. When the confining pressure was $20 \mathrm{MPa}$, it was 4.9 times greater. When the confining pressure was more than $20 \mathrm{MPa}$, it increased slowly with the increase of confining pressure. When the confining pressure reached $30 \mathrm{MPa}$, it increased by only $9.85 \%$ compared with that at $25 \mathrm{MPa}$. With the increase of the confining pressure, the residual elastic energy density also increased, indicating that the greater the confining pressure was, the less thoroughly the elastic energy of the rock dissipated during failure. At this point, the elastic energy was necessary for release for two or more times, which again 


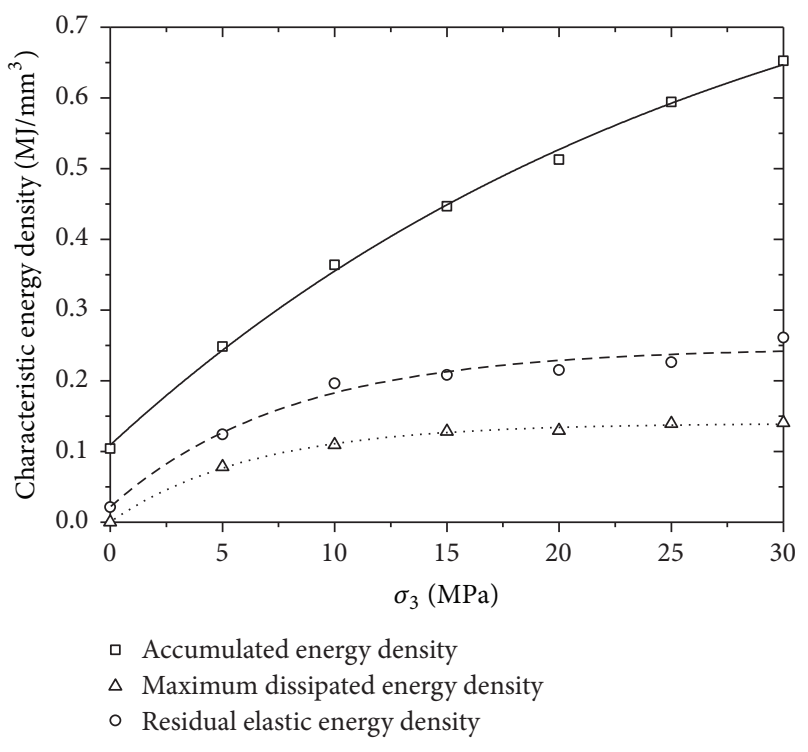

FIGURE 7: Changes of characteristic energy densities with the confining pressures.

caused a decrease of the elastic energy density curve after a certain period of stability. (2) The greater the confining pressure was, the greater the maximum dissipated energy density was. It mainly increased in the form of a power exponent. For example, the maximum dissipated energy when the confining pressure was $20 \mathrm{MPa}$ increased by 10.2 times compared with that without confining pressure, and the maximum dissipated energy at $30 \mathrm{MPa}$ increased by only $15.45 \%$ compared with that at $25 \mathrm{MPa}$. The greater the confining pressure was, the less the fracture surface formed after rock failure was. Thus, when confining pressure was high, most dissipated energy was used for the internal friction of rock plastic deformation.

\subsection{Energy Distribution Law of the Triaxial Loaded Rock} Specimens. According to (4), the input of external energy can be converted into two parts, namely, elastic energy and dissipated energy. For the same quantity of energy input, different distribution proportions have great influence on the deformation and failure modes of a rock. The distribution proportion of energy is also different under different confining pressures. Therefore, it is necessary to focus on the influence of the confining pressure on the energy distribution law of rock. The proportion of rock energy density-strain curves under triaxial cyclic loading-unloading conditions is shown in Figure 8, and the proportion of rock energy densitystrain curves under different confining pressures is shown in Figure 9.

Before the peak, the work done by the tester on rock specimens (external input energy) was mostly converted into elastic energy stored in the rock specimens, so elastic energy accounted for a large proportion. Although at this stage energy was dissipated due to compaction of pores and microcracks in rock specimens and initiation and extension of microcracks, the elastic energy that accumulated in rock specimens was much greater than the dissipated energy. Thus, the elastic energy played a dominant role, and its proportion was always greater than that of dissipated energy. In other words, the work done by the tester (external input energy) was mostly converted into elastic energy to be stored in the rock specimens. The proportion of elastic energy increased with the increase of the loading level and tended to be stable in the elastic stage. Before the peak, the rock specimens mainly accumulated elastic energy. They also dissipated a part of the energy at the same time, which caused a fluctuation of the proportions of elastic energy and dissipated energy. Thus, this stage was a dynamic energy conversion process. The greater the confining pressure was, the greater the proportion of maximum elastic energy was. The proportions of maximum elastic energy under 6 types of confining pressures were $85.12 \%, 88.35 \%, 88.24 \%, 89.85 \%, 89.73 \%$, and $91.36 \%$. Accordingly, with the increase of the confining pressure, the proportion of dissipated energy decreased, which indicated that the increase of confining pressure not only increased the intensity of energy input but also improved the efficiency of energy accumulation. If the confining pressure was unloaded suddenly at a high stress level, it would cause the release of a large amount of elastic energy and further induce rock dynamic disasters.

After the peak, when the specimen was close to rock failure, the connection and extension of microcracks in rock specimens and the formation of macro failure surfaces were needed to release elastic energy accumulated in the rock specimens, which caused a continuous increase of dissipated energy and an increase of its proportion. When loading to the peak stress of the rock and entering the postpeak stage, elastic energy accumulated in rock specimens was released instantly and converted into dissipated energy of rock failure, causing a significant increase of dissipated energy. As a result, the proportion of dissipated energy in rock specimens exceeded that of elastic energy during macro fracture. The proportions of maximum dissipated energy under 6 types of confining pressures were $63.13 \%, 61.04 \%, 56.50 \%, 54.76 \%$, $62.61 \%$, and $60.76 \%$. When loading to peak stress, the rock specimens were in a high energy unstable state. Further, the stress decreased to the residual strength, which was a sudden change process of energy conversion. A large amount of elastic energy was released during rock failure, leading to rock restructuring and a sharp reduction of elastic energy. When rock specimens were stable again, they recovered the ability to accumulate energy, and the proportion of elastic energy started to increase again. However, due to the reduction of the energy storage capacity of the rock caused by fracture, the proportion of elastic energy could not return to its previous level. The greater the confining pressure was, the lower the proportion of elastic energy reduced during peak damage, which indicated that confining pressure had an inhibitory effect on energy release. From the perspective of thermodynamics, the damage and cracking process of rock was an irreversible evolution process of the internal structure of the rock, which needed to dissipate energy. The rock behaved as a dissipative structure, formation of which required supply of external energy and the maintenance of internal energy dissipation. The heat conduction, the 

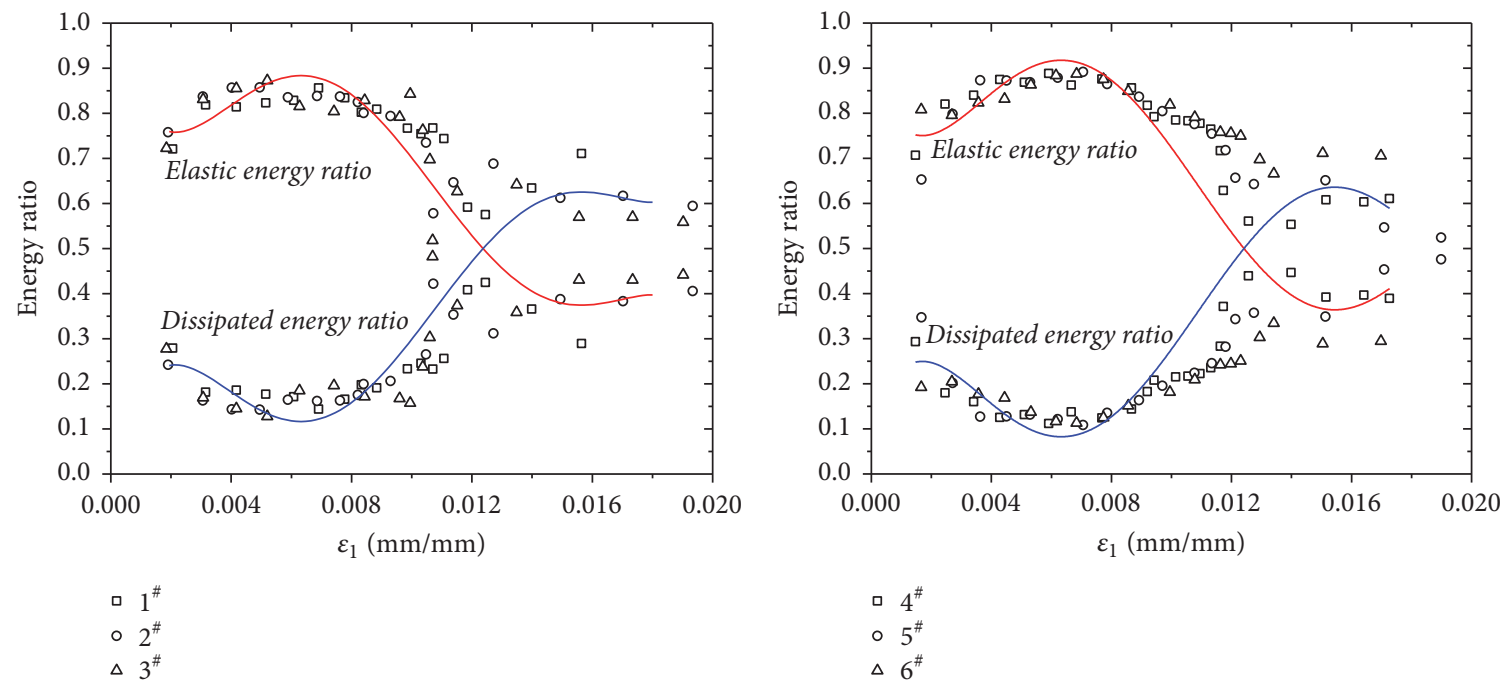

$\begin{array}{ll}\square & 4^{\#} \\ \circ & 5^{\#} \\ \Delta & 6^{\#}\end{array}$

(a) $\sigma_{3}=5 \mathrm{MPa}$

(b) $\sigma_{3}=10 \mathrm{MPa}$
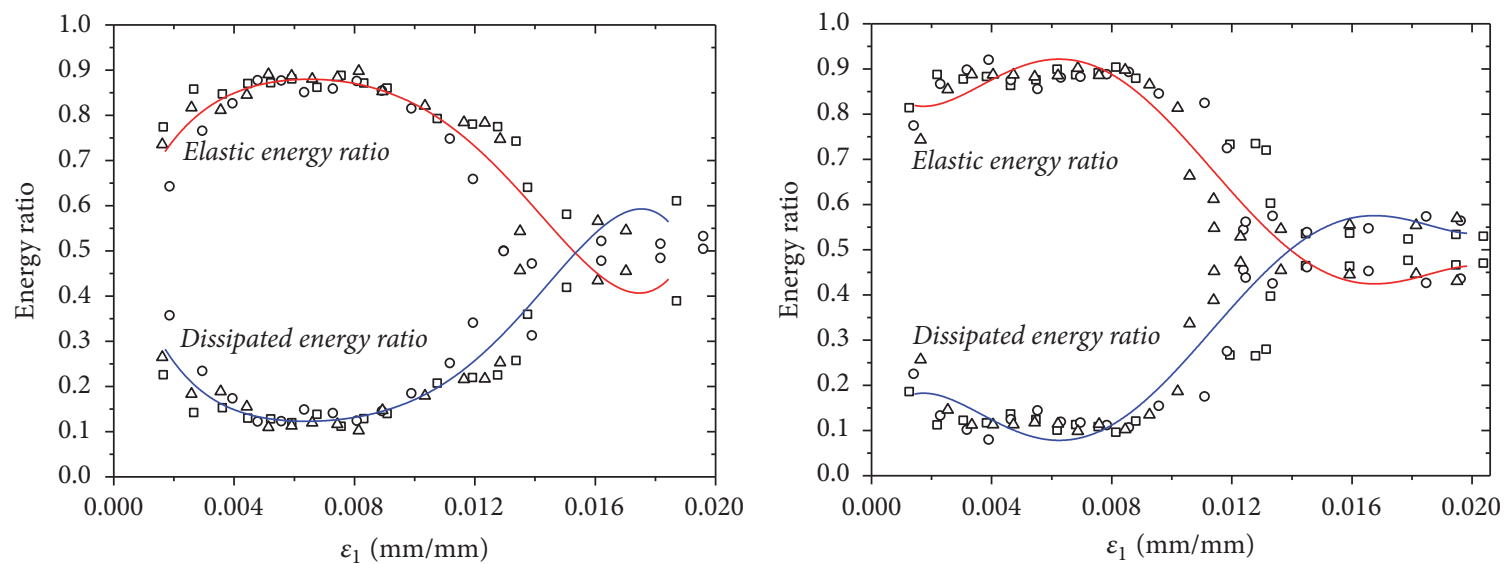

$-7^{\#}$
$\circ 8^{\#}$
$\Delta 9^{\#}$

ㅁ $10^{\#}$

- $11^{\#}$

$\triangle 12^{\#}$

(c) $\sigma_{3}=15 \mathrm{MPa}$

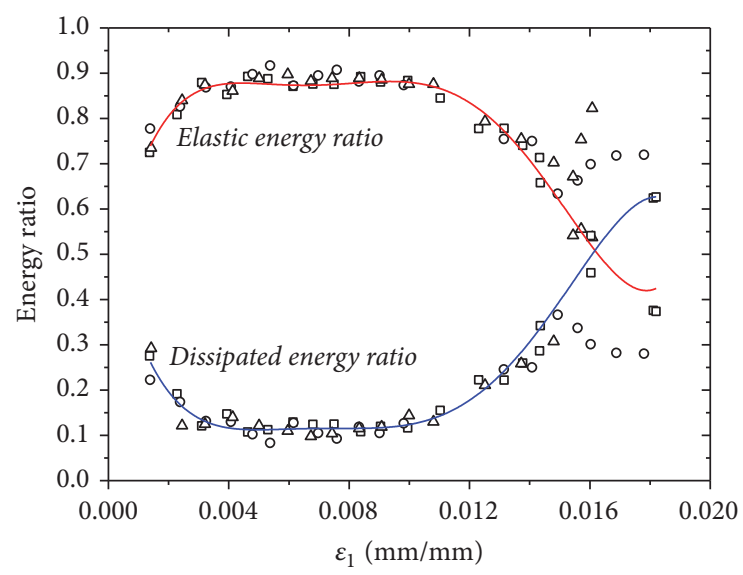

(d) $\sigma_{3}=20 \mathrm{MPa}$

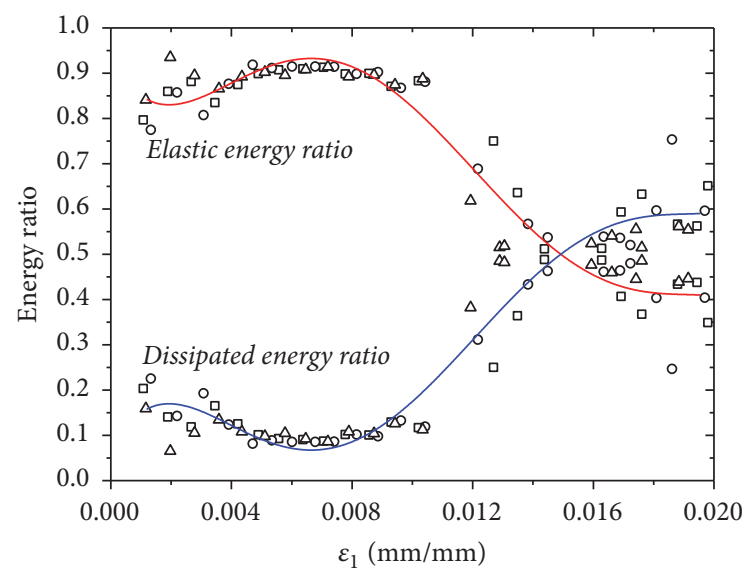

ㅁ $13^{\#}$

- $14^{\#}$

- $16^{\#}$

- $17^{\#}$

$\triangle 18^{\#}$

(e) $\sigma_{3}=25 \mathrm{MPa}$

(f) $\sigma_{3}=30 \mathrm{MPa}$

FIGURE 8: Relationships of the rock energy density percentage and the strain under the triaxial cyclic loading-unloading conditions. 


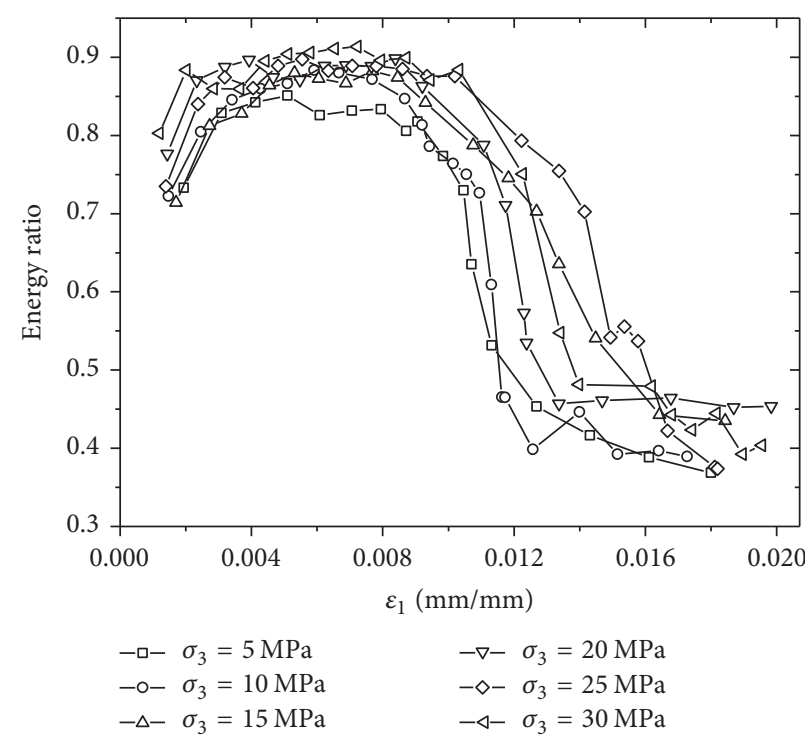

(a)

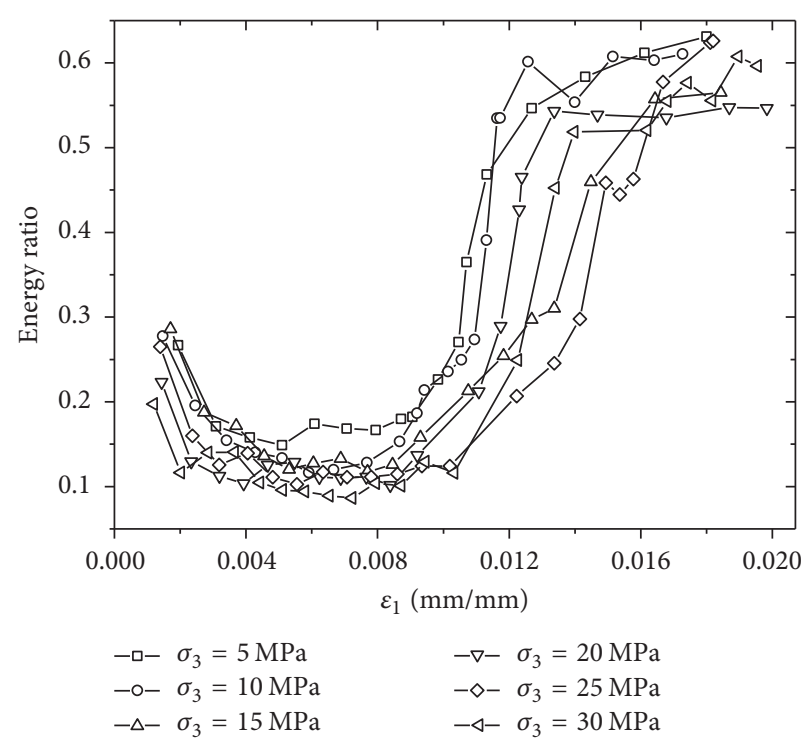

(b)

FIGURE 9: Relationships of the rock energy density percentage and the strain under the different confining pressure conditions. (a) Elastic energy density percentage versus strain; (b) dissipated energy density percentage versus strain.

change of volume unit shape and location, the production and maintenance of elastic deformation, and the formation and extension of internal microdefects and other irreversible processes in the deformation and failure of the rock all caused a high proportion of dissipated energy in the residual stage. In addition, when the load reached the residual strength, the load that the rock could bear was basically unchanged. With the increase of the load, the elastic energy accumulated in the rock remained unchanged so that the proportions of elastic energy and dissipated energy were constant. It was a steady energy conversion process.

\section{Rock Energy Conversion Mechanism in the Deformation and Failure Process}

The peak stress point is the critical point of overall failure caused by the loss of rock strength and connection of macro fracture surfaces, as well as the critical point for the conversion of elastic energy and dissipated energy. The energy density characteristics before and after the peak and at the peak point are shown in Figure 10, and specific values are detailed in Table 3.

According to Table 3, (1) before the peak, elastic energy density accounted for $60.86 \%$ to $73.28 \%$ of the total elastic energy density in the entire process. With the increase of the confining pressure, the elastic energy density before the peak also increased. When the confining pressure was $5 \mathrm{MPa}$, it was $1.47 \mathrm{MJ} / \mathrm{mm}^{3}$ before the peak; when the confining pressure was $30 \mathrm{MPa}$, it was $3.05 \mathrm{MJ} / \mathrm{mm}^{3}$ before the peak, an increase of 2.08 times. The dissipated energy density before the peak accounted for only $28.02 \%$ to $35.62 \%$ of the total dissipated energy density in the entire process. (2) At the peak point, the elastic energy density accounted for $9.69 \%$ to $15.68 \%$ of the total elastic energy density in the entire process.

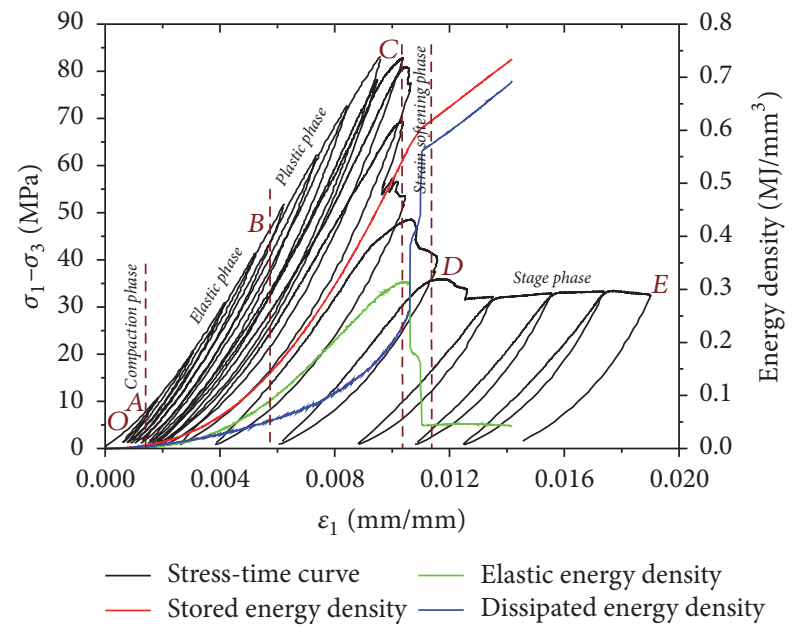

FIGURE 10: Rock energy conversion behaviors in triaxial cyclic loading-unloading compressions $\left(\sigma_{3}=10 \mathrm{MPa}\right)$.

Further, with the increase of confining pressure, the elastic energy density at the peak point also increased. When the confining pressure was $5 \mathrm{MPa}$, it was $0.25 \mathrm{MJ} / \mathrm{mm}^{3}$ at the peak point; when the confining pressure was $30 \mathrm{MPa}$, it was $0.65 \mathrm{MJ} / \mathrm{mm}^{3}$ at the peak point, an increase of 2.63 times. The dissipated energy density at the peak point accounted for $6.11 \%$ to $12.58 \%$ of the total dissipated energy density in the entire process. (3) After the peak, the elastic energy density accounted for $22.97 \%$ to $34.29 \%$ of the total elastic energy density, and the dissipated energy density accounted for $55.77 \%$ to $70.65 \%$ of the total dissipated energy density in the entire process, so the latter accounted for a large proportion after the peak. In general, the elastic energy density stored 
TABLE 3: Magnitude and percentage of the elastic energy density and the dissipated energy density around the rock failure stage.

\begin{tabular}{lccccccccccccc}
\hline & \multicolumn{4}{c}{ Prepeak phase } & \multicolumn{3}{c}{ At the stress peak } & \multicolumn{4}{c}{ Postpeak phase } \\
$\sigma_{3}(\mathrm{MPa})$ & \multicolumn{2}{c}{$u_{i}^{e}\left(\mathrm{MJ} / \mathrm{mm}^{3}\right)$} & \multicolumn{2}{c}{$u_{i}^{d}\left(\mathrm{MJ} / \mathrm{mm}^{3}\right)$} & \multicolumn{2}{c}{$u_{i}^{e}\left(\mathrm{MJ} / \mathrm{mm}^{3}\right)$} & \multicolumn{2}{c}{$u_{i}^{d}\left(\mathrm{MJ} / \mathrm{mm}^{3}\right)$} & \multicolumn{3}{c}{$u_{i}^{e}\left(\mathrm{MJ} / \mathrm{mm}^{3}\right)$} & \multicolumn{2}{c}{$u_{i}^{d}\left(\mathrm{MJ} / \mathrm{mm}^{3}\right)$} \\
& Value & $\%$ & Value & $\%$ & Value & $\%$ & Value & $\%$ & Value & $\%$ & Value & $\%$ \\
\hline 5 & 1.468 & 70.5 & 0.359 & 35.1 & 0.248 & 11.9 & 0.072 & 7.1 & 0.613 & 29.4 & 0.665 & 64.9 \\
10 & 2.261 & 60.1 & 0.515 & 2.8 & 0.364 & 9.6 & 0.112 & 6.1 & 1.288 & 34.2 & 1.025 & 55.7 \\
15 & 2.378 & 67.8 & 0.505 & 35.6 & 0.446 & 12.7 & 0.152 & 10.7 & 1.125 & 32.1 & 0.913 & 64.3 \\
20 & 2.528 & 67.6 & 0.489 & 29.8 & 0.512 & 13.7 & 0.138 & 8.4 & 1.207 & 32.3 & 1.151 & 70.1 \\
25 & 2.981 & 72.1 & 0.534 & 34.3 & 0.594 & 13.8 & 0.193 & 10.7 & 1.149 & 27.8 & 1.023 & 65.7 \\
30 & 3.051 & 73.2 & 0.507 & 29.4 & 0.652 & 15.6 & 0.216 & 12.5 & 1.112 & 26.7 & 1.215 & 70.5 \\
\hline
\end{tabular}

in rock specimens at the peak stress point was greater than the dissipated energy density used for elastic deformation and new crack surface energy, indicating that the total energy density absorbed by rock specimens before the peak was mainly stored in form of elastic energy density. The total energy density, elastic energy density, and dissipated energy density absorbed by rock specimens at the peak stress point all increased with the increase of confining pressure, so the greater the confining pressure was, the stronger the failure degree of rock specimen before peak was ( $u^{d}$ was greater) and the greater the stored elastic energy density was. After the peak, with the rapid release of elastic energy and the release of a large amount of strain energy due to elastic deformation and crack extension in the rock specimens, the dissipated energy density increased dramatically.

Based on the previously studied energy density conversion regularity of red sandstones under triaxial cyclic loadingunloading conditions and the strain energy conversion process diagram of red sandstones under such conditions, the energy conversion process mechanism of red sandstones at the prepeak compaction and elastic stage, prepeak plastic stage, postpeak strain softening stage, and postpeak residual stage from deformation to failure could be summarized.

(1) At the Prepeak Compaction and Elastic Stage. In the compaction (OA segment on the curve) and elastic stages (AB segment on the curve), rock specimens did not generate new cracks to dissipate energy, and the total energy density absorbed was mainly stored in the form of elastic energy density. At this stage, a part of the energy was dissipated due to the compression of primary pores within rock specimens or the closure of microcracks, but the dissipated energy density was too small to be considered. Therefore, elastic energy conversion regularity at compaction and elastic stage could be described as

$$
\begin{gathered}
u^{e} \approx u^{0} \\
u^{e} \gg u^{d} \\
\frac{d u^{e}}{d t}>0 \\
\frac{d u^{d}}{d t} \approx 0,
\end{gathered}
$$

where $t$ was test time, s.
(2) At the Prepeak Plastic Stage. In the initial stages of plastic deformation (initial part of the BC segment on the curve, namely, the crack stable extension stage), the strain energy absorbed by rock specimens was mostly stored in form of elastic energy density. When it was close to the peak point $\mathrm{C}$ (latter part of the BC segment, namely, the crack unstable extension stage), the dissipated energy density increased rapidly and was mainly used for the surface energy of crack extension. However, the elastic energy density stored before the peak was always greater than the dissipated energy density. The dissipated energy density rate increased significantly only close to the peak point. Therefore, the strain energy conversion regularity at the prepeak plastic stage could be described as

$$
u^{e}>u^{d}
$$

In the initial stage of plastic deformation (the crack stable extension stage), the storage rate of elastic energy density was greater than the dissipation rate of dissipated energy density; therefore, there was

$$
\begin{aligned}
& \frac{d u^{e}}{d t}>\frac{d u^{d}}{d t} \\
& \frac{d u^{e}}{d t}>0 \\
& \frac{d u^{d}}{d t}>0 .
\end{aligned}
$$

At a place near the peak point $\mathrm{C}$ (the crack unstable extension stage), the storage rate of elastic energy density was much smaller than the dissipation rate of dissipated energy density; therefore, there was

$$
\begin{aligned}
& \frac{d u^{e}}{d t}<\frac{d u^{d}}{d t} \\
& \frac{d u^{e}}{d t}>0 \\
& \frac{d u^{d}}{d t}>0 .
\end{aligned}
$$

(3) At the Postpeak Strain Softening Stage. The postpeak strain softening stage (CD segment on the curve, namely, the stress 
drop stage) was also the overall rock failure process. At this stage, the dissipation rate of strain energy density absorbed by rock specimens was equal to that of dissipated energy density. It was mainly converted into crack surface energy for rapid crack extension and run-through after the peak. Due to the rapid decrease of stress after the peak, the elastic energy was released quickly, and the release rate of elastic energy density was greater than that of dissipated energy density. Therefore, strain energy conversion regularity at the postpeak strain softening stage could be described as

$$
\begin{gathered}
\left|\frac{d u^{e}}{d t}\right| \gg \frac{d u^{d}}{d t} \\
\frac{d u^{0}}{d t} \approx \frac{d u^{d}}{d t} \\
\frac{d u^{e}}{d t}<0 \\
\frac{d u^{d}}{d t}>0 .
\end{gathered}
$$

(4) At the Postpeak Residual Stage. When loading to the residual strength (DE segment on the curve), with continuous loading, the load borne by the rock specimens was basically unchanged, which caused the elastic energy accumulated in the rock to maintain a constant level. The release rate of elastic energy density was zero. However, there were still a small number of microcracks generated in the loading process, which led to a slight increase of dissipated energy. Therefore, the strain energy conversion regularity at the postpeak residual stage could be described as

$$
\begin{aligned}
& \frac{d u^{d}}{d t} \gg \frac{d u^{e}}{d t} \\
& \frac{d u^{e}}{d t} \approx 0 \\
& \frac{d u^{d}}{d t}>0 .
\end{aligned}
$$

In general, the deformation and failure process of rock is a unified process of energy transfer and conversion accompanied by energy accumulation, dissipation, and release. Energy conversion and loss are the essence of rock deformation and failure, corresponding to microcrack closure, new microcrack extension, run-through, and formation of main cracks. In this process, the rock strength is decreased, which makes the rock finally lose its bearing capacity. With changes of the stress state and the development of deformation, the energy state of rock continues to change, and microdefects in the rock evolve from a disordered distribution to an orderly development to form macro cracks. Eventually, macro cracks accumulate to large cracks along a particular direction, which causes overall instability.

\section{Discussion on Energy Evolution Path of the Dynamic Disturbed Rock in Engineering}

Unlike the constant confining pressure in rock experiments in the lab, the stress path of rock in engineering practice is always very complex. The coal seam mining stress path in coal mining, for example, as shown in Figure 11, can be basically divided into 4 stages [28]: stage 1: the coal-rock mass in front of the working face before mining disturbance can be regarded as being under the hydrostatic pressure state $\left(\sigma_{1}\right.$ $=\sigma_{2}=\sigma_{3}=\gamma H$, where $\sigma_{1}$ is the vertical stress or abutment pressure; $\sigma_{2}$ and $\sigma_{3}$ are the horizontal stresses; $\gamma$ is the weight of rock strata; and $H$ is the mining depth); stage 2: with the progress of mining work, the distance from the working face is increasingly shortened, causing a gradual reduction of the horizontal stress $\left(\sigma_{2}=\sigma_{3}=\lambda \gamma H\right.$, where $\lambda$ is the lateral pressure coefficient), and the vertical stress $\left(\sigma_{1}=K \gamma H\right.$, where $K$ is the stress concentration coefficient) increases gradually; stage 3: the vertical stress increases to the peak point, causing destruction of the coal-rock mass; and stage 4: the horizontal stress is gradually unloaded to 0 , and the vertical stress is reduced to the uniaxial residual strength $\left(\sigma_{r}\right)$ at the coal wall.

The representation of the mining stress path on a conventional triaxial stress-strain curve is shown in Figure 12. The initial state can be considered as the hydrostatic stress state. Later, the increase of axial pressure and the reduction of confining pressure mean that the mining stress-strain curve moves from a high-confining pressure curve to a lowconfining pressure curve until the axial pressure is just equal to the peak stress under the current confining pressure. At this time, rock begins to enter the failure stage, and axial pressure begins to decrease. The confining pressure is loaded continuously to make the mining stress-strain point continue moving to a stress-strain curve under a lower confining pressure until reaching the residual strength point under uniaxial loading to finish a complete mining stress path.

According to rock energy behavior and its confining pressure effect, we can provide a simple discussion on its energy path under mining conditions. The rock under a specific confining pressure has a storage limit. It undergoes unstable failure if it reaches the limit value and is disturbed. Figure 13 is the energy storage limit curve. The initial stress is set to be $\sigma_{0}$ at point $\mathrm{D}$. There are many energy paths to failure. Different confining pressures and loading-unloading methods for axial pressure can cause differences in the energy path. Under different initial stresses, the stress paths needed to reach the same energy state are also different. On the whole, however, they all achieve it through a combination of 2 paths, namely, increasing the energy storage level and decreasing the energy storage limit. Generally, there are 3 typical energy paths: path DC shows axial loading under constant confining pressure, corresponding to pseudotriaxial rock tests; path DB is the shortest path from D to the energy storage limit curve, perhaps corresponding to a quasi-static continuous loading method. The path DA directly evolves to failure under a uniaxial stress state. There is no failure before it. It may correspond to an unloading failure process under the dominance of the confining pressure. From the perspective of energy, 3 conditions are needed for rock to undergo dynamic 


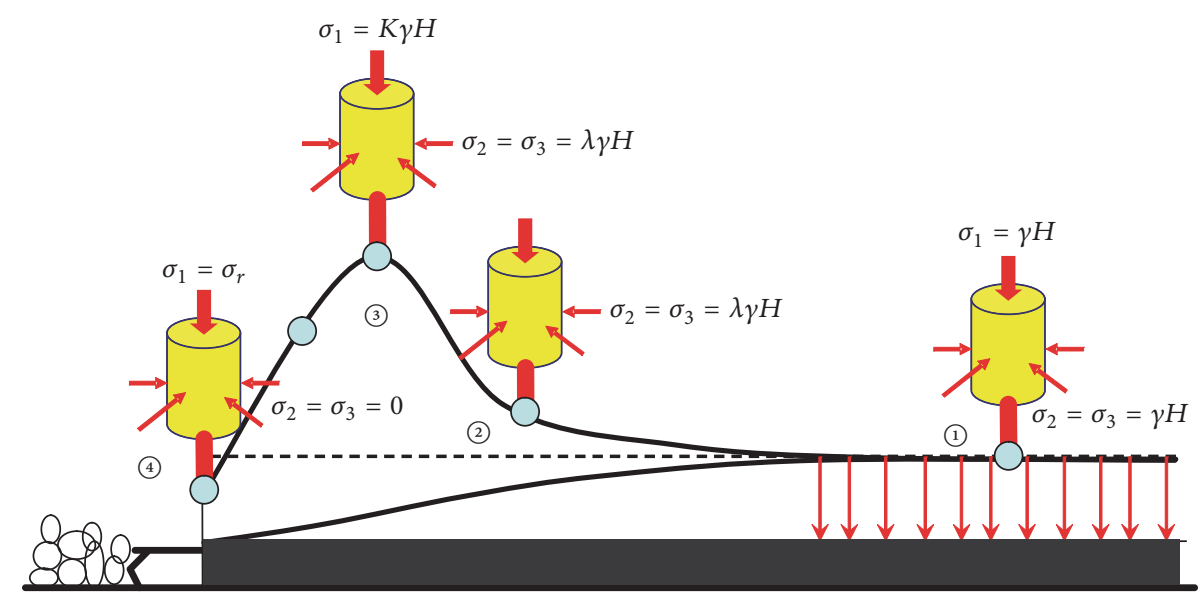

FIGURE 11: Stress distribution and migration in the underground coal mining face.

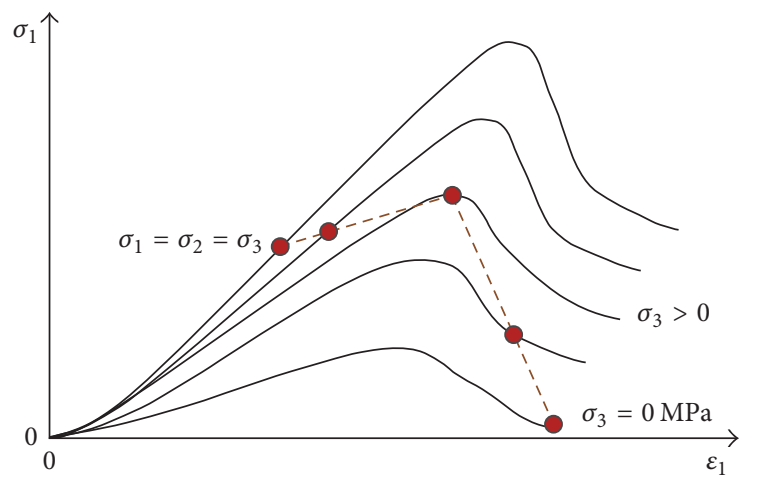

FIGURE 12: Mining-disturbed stress path reflected in the conventional triaxial stress-strain curves.

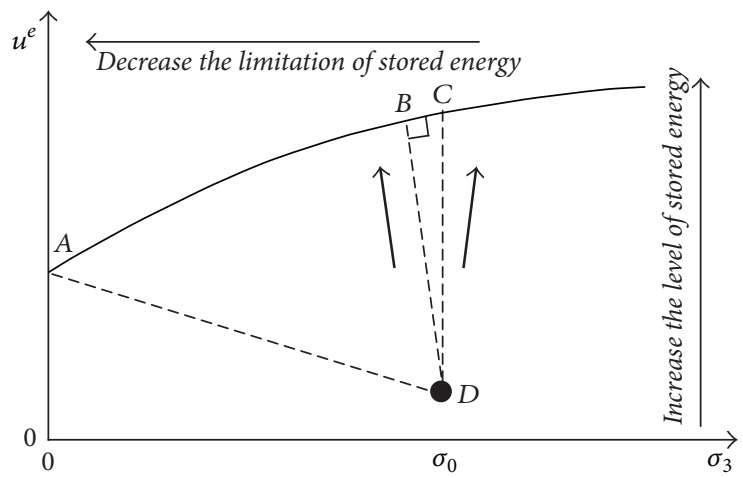

FIGURE 13: Energy evolution path in mining-disturbed rock masses.

instability: (1) the rock stores a large amount of elastic energy; (2) the rock reaches the energy limit and suffers failure; (3) energy must be released rapidly and in large amounts during failure. Therefore, a large slope for the energy path indicates that the rock has reached the critical state under the condition of high energy storage. At this point, it is easier to induce strong energy release behavior due to the sudden unloading of the confining pressure and to further cause dynamic disasters.

\section{Conclusions}

Through triaxial cyclic loading-unloading experiments on sandstones under 6 types of confining pressures, the influence of the confining pressure on the axial energy evolution and the distribution laws was obtained. On this basis, rock energy conversion equations at different stress-strain stages and the energy evolution path under mining conditions were discussed. The following conclusions were drawn.

(1) Rock deformation and failure is essentially a process of energy dissipation and release. It takes energy release as its source power at the moment of sudden change of a rock in the stable state. Under cyclic loading-unloading, red sandstones reflected obvious plastic-loop phenomena, indicating that the work done by the tester was not completely converted into rock elastic energy but a part of it was released in the forms of failure energy and plastic energy.

(2) Before the peak, the rock energy behavior was mainly displayed as energy accumulation. The elastic energy density increased slowly at first and then rapidly. When it was close to failure, the growth rate of the dissipated energy density was greater. After the peak, the elastic energy density dramatically decreased, and the dissipated energy density significantly increased, which was mainly embodied in energy dissipation and release. With the increase of the confining pressure, the characteristic energy density parameters of the rock were basically increased in the form of power exponents, indicating that the rock energy storage limit density increased, but the elastic energy was not fully released during postpeak failure, and most dissipated energy was used for plastic deformation of rock specimens.

(3) The proportion of elastic energy before the peak was always greater than that of dissipated energy, and most of the work done by the tester was converted into elastic energy and stored in rocks. After the peak, the proportion of dissipated energy exceeded that of elastic energy when macro cracks occurred in the rock specimens. With the increase 
of the confining pressure, the proportion of the maximum elastic energy increased, indicating that confining pressure improved the efficiency of energy accumulation. The greater the confining pressure was, the smaller the proportion of elastic energy decreased during peak failure, which indicated that confining pressure inhibited the degree of energy release.

(4) The study analyzed the energy mechanism of red sandstones in the deformation and failure process and established energy conversion equations in the prepeak compaction and elastic stage, prepeak plastic stage, postpeak strain softening stage, and postpeak residual stage. The rock energy path from deformation to failure was achieved through a combination of increasing energy storage level and decreasing energy storage limit. The great slope of the energy path indicated that the rock had reached its critical state in the case of high energy storage. At this point, it was easier to induce strong energy release behavior due to the sudden unloading of the confining pressure.

\section{Symbols}

$U$ : Internal energy increment of the system, $\mathrm{J}$

Q: Heat exchange between the system and the environment, J

$W$ : Work exchange between the system and the environment, $\mathrm{J}$

$\sigma_{1}:$ Axial stress, $\mathrm{MPa}$

$\sigma_{3}$ : Confining pressure, $\mathrm{MPa}$

$\sigma^{\prime}$ : Stress at any point of stress-train curve, $\mathrm{MPa}$

$\varepsilon^{\prime}$ : Strain corresponding to $\sigma^{\prime}, \mathrm{mm} / \mathrm{mm}$

$\varepsilon^{\prime \prime}$ : Strain when $\sigma^{\prime}$ is unloaded to $0, \mathrm{~mm} / \mathrm{mm}$

E: Elastic, MPa

$\mu$ : Poisson's ratio

$u^{0}$ : Total energy, J

$u^{e}$ : Elastic energy aggregated in rock, $\mathrm{J}$

$u^{d}$ : Energy dissipated by the rock in loading process, J

$u_{1}^{0}$ : Absorbed energy in rock compression and deformation under the axial stress $\sigma_{1}, \mathrm{~J}$

$u_{2}^{0}$ : Energy dissipated in the rock deformation and expansion when doing negative work under the confining pressure $\sigma_{3}, \mathrm{~J}$

$u_{3}^{0}$ : Energy absorbed by the rock in the hydrostatic stress state, $\mathrm{J}$

$t$ : Testing duration, $\mathrm{s}$.

\section{Conflicts of Interest}

The authors declare that there are no conflicts of interest.

\section{Authors' Contributions}

Shengdong Liu and Mingwei Zhang conceived and designed the experiments; Qingbin Meng and Mingwei Zhang performed the experiments; Shengdong Liu, Qingbin Meng, and Mingwei Zhang analyzed the data; Mingwei Zhang wrote the paper.

\section{Acknowledgments}

The financial support and general support for this research provided by the Fundamental Research Funds for the Central Universities (no. 2015QNA62) and the National Key R\&D Program of China (no. 2016YFC0600900) are gratefully acknowledged. This fund covers the costs to publish the work in open access.

\section{References}

[1] H. Xie, L. Li, Y. Ju, R. Peng, and Y. Yang, "Energy analysis for damage and catastrophic failure of rocks," Science China Technological Sciences, vol. 54, no. 1, pp. 199-209, 2011.

[2] M. He, L. R. E. Sousa, T. Miranda, and G. Zhu, "Rockburst laboratory tests database - Application of data mining techniques," Engineering Geology, vol. 185, pp. 116-130, 2015.

[3] Y. Jiang, H. Wang, S. Xue, Y. Zhao, J. Zhu, and X. Pang, "Assessment and mitigation of coal bump risk during extraction of an island longwall panel," International Journal of Coal Geology, vol. 95, pp. 20-33, 2012.

[4] X. S. Liu, J. G. Ning, Y. L. Tan, and Q. H. Gu, "Damage constitutive model based on energy dissipation for intact rock subjected to cyclic loading," International Journal of Rock Mechanics and Mining Sciences, vol. 85, pp. 27-32, 2016.

[5] A. V. Mikhalyuk and V. V. Zakharov, "Dissipation of dynamicloading energy in quasi-elastic deformation processes in rocks," Journal of Applied Mechanics and Technical Physics, vol. 38, no. 2, pp. 312-318, 1997.

[6] V. Sujatha and J. M. Chandra Kishen, "Energy release rate due to friction at bimaterial interface in dams," Journal of Engineering Mechanics, vol. 129, no. 7, pp. 793-800, 2003.

[7] E. D. Steffler, J. S. Epstein, and E. G. Conley, "Energy partitioning for a crack under remote shear and compression," International Journal of Fracture, vol. 120, no. 4, pp. 563-580, 2003.

[8] H. Munoz, A. Taheri, and E. K. Chanda, "Rock drilling performance evaluation by an energy dissipation based rock brittleness index," Rock Mech Rock Eng, vol. 49, no. 8, pp. 33433355, 2016.

[9] C. E. Tsoutrelis and G. E. Exadaktylos, "Effect of rock discontinuities on certain rock strength and fracture energy parameters under uniaxial compression," Geotechnical and Geological Engineering, vol. 11, no. 2, pp. 81-105, 1993.

[10] E. Gaziev, "Rupture energy evaluation for brittle materials," International Journal of Solids and Structures, vol. 38, no. 42-43, pp. 7681-7690, 2001.

[11] D. J. Holcomb, "Memory, relaxation, and microfracturing in dilatant rock." Journal of Geophysical Research: Atmospheres, vol. 86, no. 7, pp. 6235-6248, 1981.

[12] A. N. Tutuncu, A. L. Podio, A. R. Gregory, and M. M. Sharma, "Nonlinear viscoelastic behavior of sedimentary rocks, Part I: Effect of frequency and strain amplitude," Geophysics, vol. 63, no. 1, pp. 184-194, 1998.

[13] A. N. Tutuncu, A. L. Podio, and M. M. Sharma, "Nonlinear viscoelastic behavior of sedimentary rocks, Part II: Hysteresis effects and influence of type of fluid on elastic moduli," Geophysics, vol. 63, no. 1, pp. 195-203, 1998.

[14] T. Wong, H. Szeto, and J. Zhang, "Effect of loading path and porosity on the failure mode of porous rocks," Applied Mechanics Reviews, vol. 45, no. 8, pp. 281-289, 1992. 
[15] V. Hajiabdolmajid, P. K. Kaiser, and C. D. Martin, "Modelling brittle failure of rock," International Journal of Rock Mechanics and Mining Sciences, vol. 39, no. 6, pp. 731-741, 2002.

[16] Y. Deng, M. Chen, Y. Jin, and D. Zou, “Theoretical analysis and experimental research on the energy dissipation of rock crushing based on fractal theory," Journal of Natural Gas Science and Engineering, vol. 33, pp. 231-239, 2016.

[17] X. B. Li, T. S. Lok, and J. Zhao, "Dynamic characteristics of granite subjected to intermediate loading rate," Rock Mechanics and Rock Engineering, vol. 38, no. 1, pp. 21-39, 2005.

[18] Z. X. Zhang, S. Q. Kou, L. G. Jiang, and P.-A. Lindqvist, "Effects of loading rate on rock fracture: fracture characteristics and energy partitioning," International Journal of Rock Mechanics and Mining Sciences, vol. 37, no. 5, pp. 745-762, 2000.

[19] Y. Li, D. Huang, and X. Li, "Strain rate dependency of coarse crystal marble under uniaxial compression: Strength, deformation and strain energy," Rock Mechanics and Rock Engineering, vol. 47, no. 4, pp. 1153-1164, 2014.

[20] F. Gao, Z. Zhang, and X. Liu, "Research on rock burst proneness index based on energy evolution in rock," Disaster Advances, vol. 5, no. 4, pp. 1367-1371, 2012.

[21] Q. Meng, M. Zhang, L. Han, H. Pu, and H. Li, "Effects of size and strain rate on the mechanical behaviors of rock specimens under uniaxial compression," Arabian Journal of Geosciences, vol. 9, no. 8, article 527, pp. 1-14, 2016.

[22] Q. Meng, M. Zhang, L. Han, H. Pu, and T. Nie, "Effects of Acoustic Emission and Energy Evolution of Rock Specimens Under the Uniaxial Cyclic Loading and Unloading Compression," Rock Mechanics and Rock Engineering, vol. 49, no. 10, pp. 3873-3886, 2016.

[23] A.-Z. Hua and M.-Q. You, "Rock failure due to energy release during unloading and application to underground rock burst control," Tunnelling and Underground Space Technology, vol. 16, no. 3, pp. 241-246, 2001.

[24] R. Peng, Y. Ju, J. G. Wang, H. Xie, F. Gao, and L. Mao, "Energy Dissipation and Release During Coal Failure Under Conventional Triaxial Compression," Rock Mechanics and Rock Engineering, vol. 48, no. 2, pp. 509-526, 2014.

[25] Y. Yang, Y. Ju, F. Li, F. Gao, and H. Sun, "The fractal characteristics and energy mechanism of crack propagation in tight reservoir sandstone subjected to triaxial stresses," Journal of Natural Gas Science and Engineering, vol. 32, pp. 415-422, 2016.

[26] Y. Ju, H. J. Wang, Y. M. Yang, Q. A. Hu, and R. D. Peng, "Numerical simulation of mechanisms of deformation, failure and energy dissipation in porous rock media subjected to wave stresses," Science China Technological Sciences, vol. 53, no. 4, pp. 1098-1113, 2010.

[27] D. Song, E. Wang, and J. Liu, "Relationship between EMR and dissipated energy of coal rock mass during cyclic loading process," Safety Science, vol. 50, no. 4, pp. 751-760, 2012.

[28] H. P. Xie, H. W. Zhou, J. F. Liu et al., "Mining-induced mechanical behavior in coal seams under different mining layouts," J China Coal Soc, vol. 36, no. 7, pp. 1067-1074, 2011. 

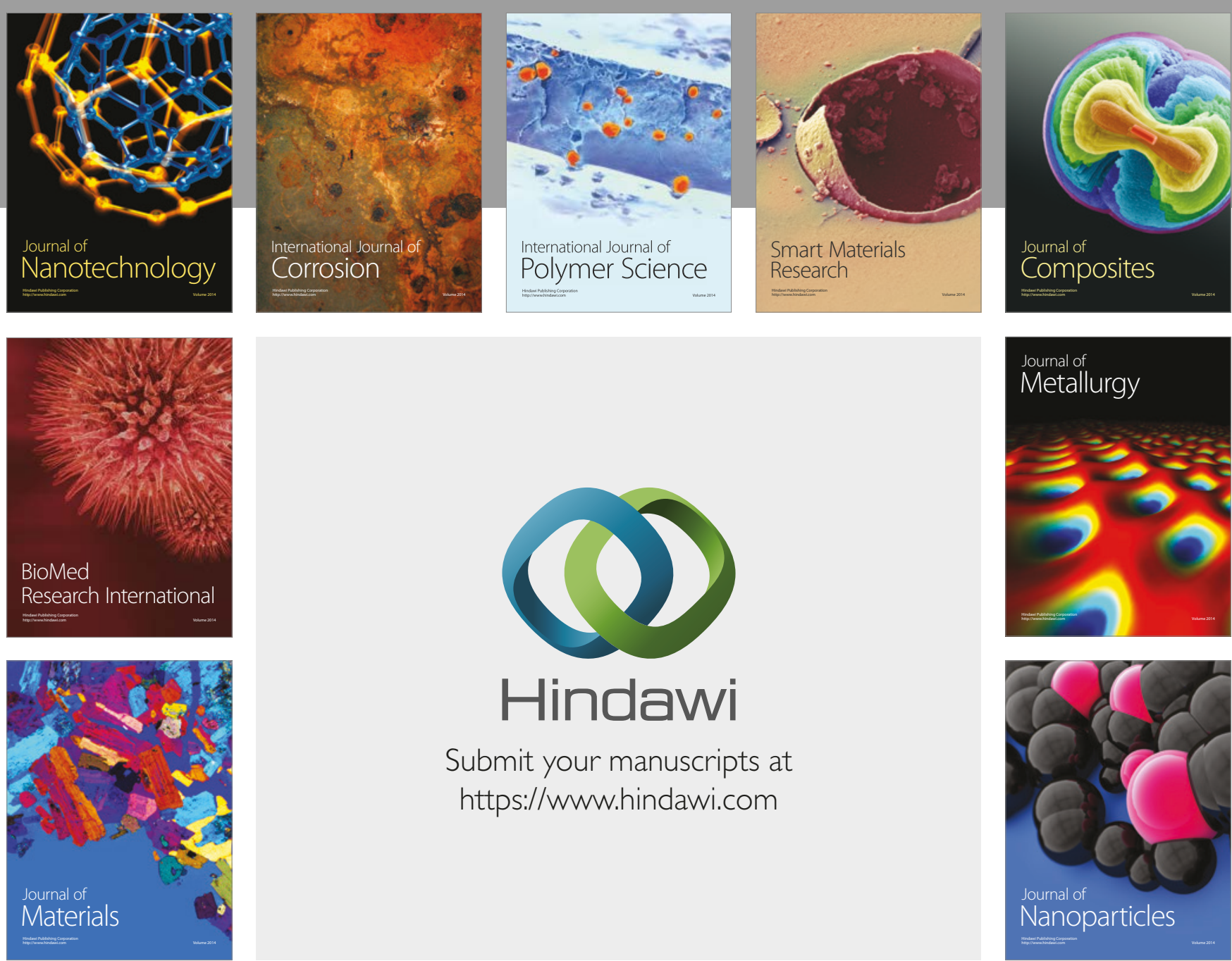

\section{Hindawi}

Submit your manuscripts at

https://www.hindawi.com
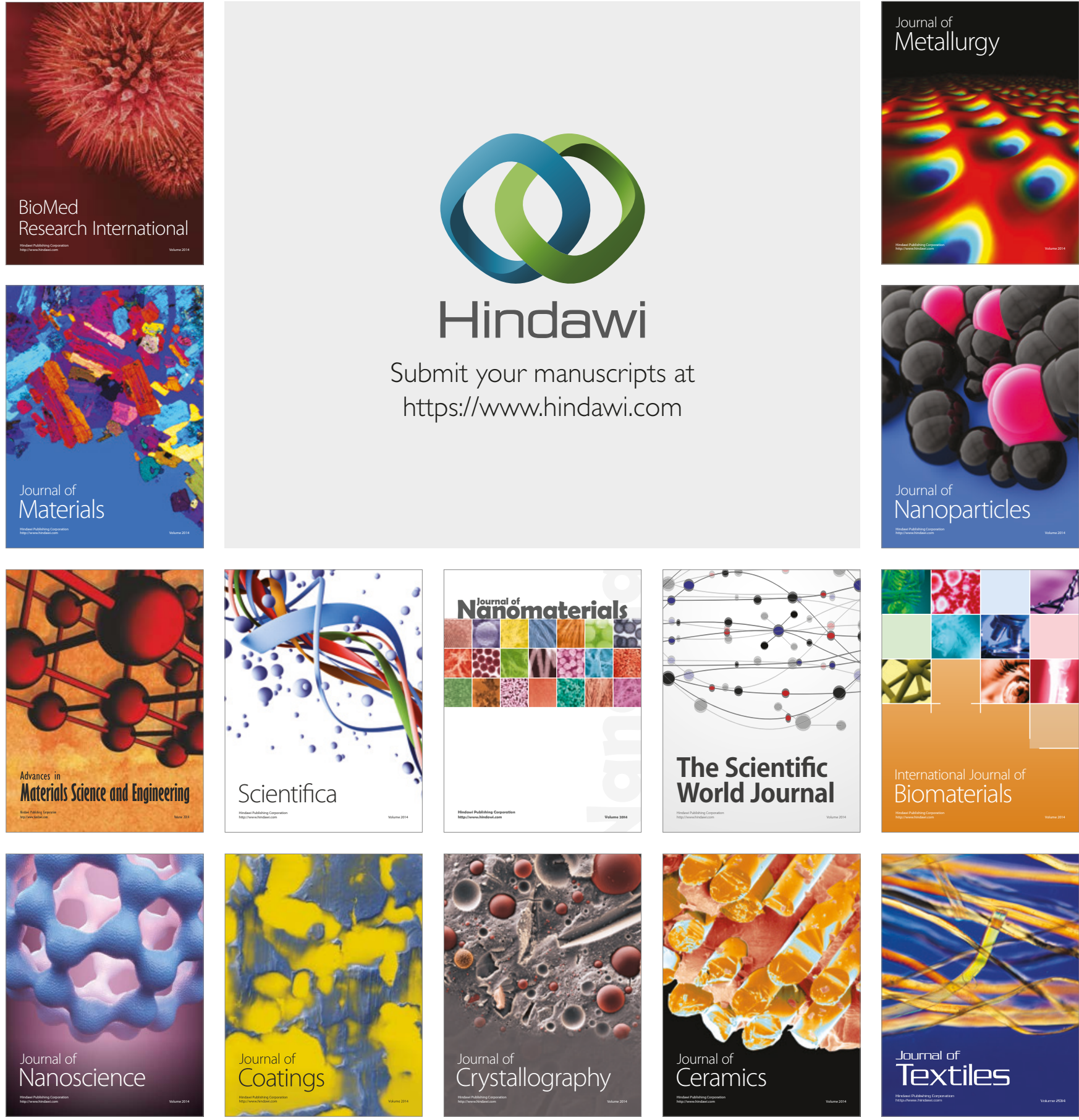

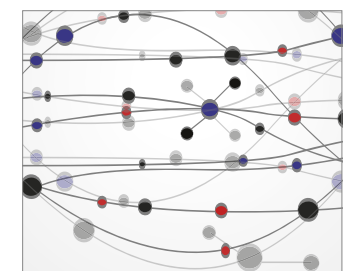

The Scientific World Journal
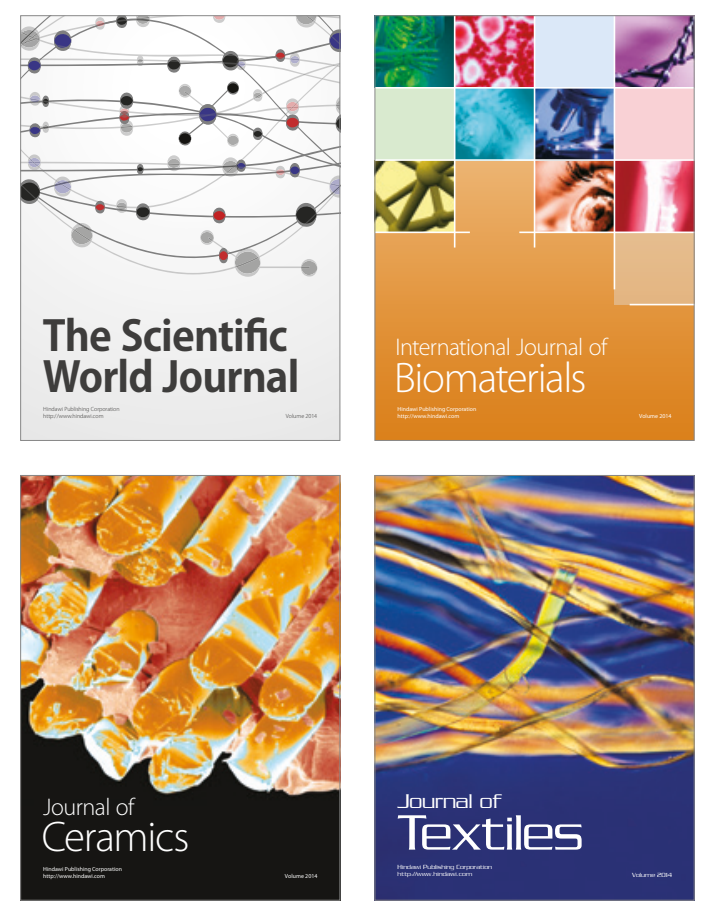